Research Article

\title{
ADVERSE EFFECTS OF DELTAMETHRIN ON THE CEREBELLUM OF MOTHERS RATS AND THEIR OFFSPRING AND THE POSSIBLE AMELIORATIVE ROLE OF MELATONIN
}

\author{
Abd El-Fattah BM El-Beltagy ${ }^{*}$, Kadry AM Elbakry ${ }^{2}$, Mohamed MA Elghazaly ${ }^{1}$, Lashin S Ali ${ }^{3}$ and \\ Norhan HM EL Daqaqq ${ }^{1}$
}

${ }^{1}$ Department of Zoology, Faculty of Science, Damanhour University, Damanhour, Egypt

${ }^{2}$ Department of Zoology, Faculty of Science, Damieta University, Damieta, Egypt

${ }^{3}$ Department of Physiology, Faculty of Medicine, Mansoura University, Egypt

Article History: Received 28th August, 2019; Accepted 06th September, 2019; Published 16th September, 2019

\begin{abstract}
Deltamethrin is the most famous neurotoxic synthetic pyrethroid. The present work was mainly designed to evaluate the possible ameliorative role of melatonin against deltamethrin induced cerebellar neurotoxicity in pregnant rats and their offspring. In the present work, 24 pregnant Albino rats were divided into four groups $(\mathrm{n}=6)$. The control group received $1 \mathrm{ml} / \mathrm{kg}$ bw of ethanol $(99 \%)$, the melatonin group received a daily oral dose of melatonin $(10 \mathrm{mg} / \mathrm{kg} \mathrm{bw})$, deltamethrin treated group was received $12.5 \mathrm{mg} / \mathrm{kg}$ bw daily of deltamethrin and ameliorative group received deltamethrin simultaneously with melatonin. All groups were received their applicable dose from the 4th day of gestation till the end of weaning period (21 $1^{\text {th }}$ day). The result of the present work revealed that deltamethrin can induce severe histopathological changes in the cerebellar cortex of pregnant rats and their offspring. The immunohistochemical results elucidated strong positive expression for GFAP and weak to moderate immune reaction for synaptophysin in the cerebellar cortex of deltamethrin treated mother's rats and their offspring. Moreover, in deltamethrin treated rats, the serum levels of antioxidants enzymes (SOD, CAT and GSH) as well as serotonin and glutamate showed highly significant decrease if compared with control. Cerebellar tissue analysis revealed that deltamethrin is implicated in induction of apoptosis that confirmed by increased activity of Caspse- 3 and decreased activity of bcl2. Post supplementation of melatonin to deltamethrin, successfully ameliorated the adverse histopathological, immmunohistochemical and biochemical changes in cerebellum of mother's rats and their offspring.
\end{abstract}

Keywords: Deltamethrin; Melatonin; Cerebellum; Histology; Antioxidants; Apoptosis

\section{INTRODUCTION}

Several neurotoxic agents like heavy metals, natural toxins, pesticides and alcohol can affect the structure and function of both developing and mature nervous system (Ascherio et al., 2006). Neurotoxic agents act mainly through penetration of the blood brain barrier (BBB) and induce several neurodegenerative effects in brain (Baldi et al., 2003).

According to World Health Organization (WHO) report, pesticide can cause toxic effects for about 3 million persons occur annually and killing about $250-370,000$ people especially in developing countries (Varol et al., 2016). Deltamethrin is one of the most famous synthetic pyrethroids that considered as the most potent neurotoxic insecticide (Soderlund et al., 2000; Tu et al., 2007). Deltamethrin (DLT) may cause various deleterious effects like hepatotoxicity and nephrotoxicity (Gündüz et al., 2015), male infertility (Oda \& El-Maddawy, 2012), change in DNA structure and antioxidants deficiency (Gasmi et al., 2016). Deltamethrin can induce the apoptotic mechanism via activation of mitochondria mediated apoptosis (Khalatbary et al., 2015; Kumar et al., 2018).

Gestational exposure to deltamethrin can also affect the development and behavioral parameters of the rat offspring's (Joya \& Sangha, 2016). Moreover, neonatal exposure to pyrethroids even at relatively low doses, affect the normal neurogenesis in the brain (Patro \& Patro, 2005). Further study revealed that, administration of deltamethrin to the neonatal rats was found to have toxic effects on cerebellum through inhibition of granule cells migration (Patro \& Patro, 2005) and survival of Purkinje cells (Latuszyñska et al., 2001; Abdel-Rahman et al., 2004).

Deltamethrin toxicity has been recorded in experimental animals like mice, rat, rabbit and guinea pig. Toxicity signs were represented by excessive salivation, defect in limb function, ataxia, loss of righting reflex, choreoathetosis, paralysis and convulsions (Narahashi, 2000; Soderlund et al., 2002). Deltamethrin can induce brain toxicity through inhibition of antioxidants activities like glutathione (GSH), superoxide dismutase (SOD) and catalase (CAT) with subsequent increase in MDA leading to severe brain damage (Gasmi et al., 2016). Takasaki et al. (2013) reported that deltamethrin reduces acetylcholinesterase (ACh) activity in the blood.

Melatonin (N-acetyl-5-methoxytryptamine) is a powerful endogenous antioxidant hormone that secreted mainly from the pineal gland and other organs like retina, gastrointestinal tract, and skin (Pang \& Allen, 1986; Acuña-Castroviejo et al., 2014). Melatonin can reduce oxidative stress and inflammation via removing of hydroxyl radicals and cytokines (Tahan et al., 2009; Chawla \& Rao, 2012). In addition, melatonin is essential 
for regulation of seasonal reproduction and pigmentation through regular release of dopamine (Dubocovich, 1983; Wiechmann, 1986). Melatonin is unusual antioxidants, because it easily diffuses into all body cells, and even crosses the BBB to protect the neurons against damage (Suzen, 2006). Furthermore, melatonin have neuroprotective properties in different brain regions including cerebellum (Uyanikgil et al., 2007). Accordingly, it had been found that deficiency of melatonin secretion leads to neurodegenerative diseases like Alzheimer's disease and cerebral stroke (Cardinali et al., 2005). The neuro-protective effect of melatonin on brain is mainly attributed to its unique interactions with specific receptors leading to maintenance of neuronal cells (Kabadi and Maher, 2010). Moreover, melatonin can maintain cellular homeostasis and survival by modulating inflammation and apoptosis following various types of brain injury (Fernández et al., 2015). Other studies have revealed that injection of melatonin in induced subarachnoid hemorrhage reduced brain edema and improved neurological disorders (Dong et al., 2016). Reiter et al. (2005) proved that injection of melatonin at the time of stroke could limit the area of brain tissue damage and reduced brain cell death. Accordingly this work was mainly designed to evaluate the possible ameliorative role of melatonin against deltamethrin induced cebellar neurotoxicity of pregnant rats and their offspring.

\section{MATERIALS AND METHODS}

\section{Chemicals}

Deltamethrin (98\%) and Melatonin (white crystals) were purchased from Sigma Pharmaceutical Company.

\section{Experimental design}

Experimental animals: For this study, thirty-two (24 females and 8 males) Wistar albino rats weighing 180-200 g (8-9 weeks) were obtained from the Holding Company for Biological Products and Vaccines (VACSERA, Cairo, Egypt). The animals were kept in wire- bottomed cages in a room under standard condition of illumination with a 12-hours light-dark cycle at $25 \pm 1{ }^{\circ} \mathrm{C}$ and $50 \%$ relative humidity. They were provided with tap water and balanced diet of libitum. After an acclimatization period of two weeks; the animals were mated in the special matting cages (1 male: 3 females) overnight. After 3-4 days and ensuring of pregnancy via observation of vaginal plug and using vaginal smear method, pregnant females were separated from males.

Mother rats were weighed at the beginning of the experiment, at birth and at postnatal day (PND) 21 (weaning). On the day of birth (PND0), we recorded the number of pups and weight of the offspring. Pups also, were weighed at birth, at PNDs 21 days.

Experimental groups: The pregnant rats were randomly divided into four groups as follows, six for each group $(n=6)$.

Group I (control): They were received $1 \mathrm{ml} / \mathrm{kg}$ bw of ethanol (99\%) (a melatonin solvent) daily by I.P injection. Ethanol must be diluted with saline just before injection with final concentration of ethanol was $2 \%$ according to Crespi et al. (1994).
Group II (Melatonin-treated group): they were given a daily oral dose of melatonin (10 mg/kg bw daily I.P) according to Hala et al., 2009. Melatonin was dissolved in $99 \%$ ethanol then diluted with saline just before injection with final concentration of ethanol was 2\% (Crespi et al., 1994).

Group III (Deltamethrin- treated group): pregnant rats were received deltamethrin dissolved in corn oil at a dose of $12.5 \mathrm{mg} /$ $\mathrm{kg}$ bw daily I.P according to Aiguo and Yugu, (2000). This dose is $15 \%$ of LD50 of deltamethrin (Sheets et al., 1994)

Group IV (Deltamethrin \& Melatonin-treated group): the pregnant rats were given deltamethrin simultaneously with melatonin by the same previous doses.

All groups were exposed to the appropriate dose of treatment from the 4th day of pregnancy till the end of weaning. The offspring of all groups were weighed and examined at the ages of three weeks.

Sample collection and tissue preparation: At the end of the experimental period $\left(21^{\text {th }}\right.$ days postnatal), the fasted rats sacrificed and the blood was collected for estimation of antioxidants and some hormones. The animals were dissected and the whole brain of mother's rats and their offspring were removed immediately, washed in normal saline. The cerebellum was separated from each brain then, cut longitudinally into two equal halves; one half was kept frozen for estimation of tissue biochemical parameters while the other was fixed in 10\% neutral buffered formalin for histological and immunohistochemical studies.

\section{Investigated parameters}

Histological technique for haematoxylin and eosin stain: Formalin fixed cerebella were dehydrated with an ascending ethanol series, cleared with xylene, and embedded in paraffin. The 5-6 $\mu \mathrm{m}$ thick longitudinal sections of cerebellum were obtained then stained with hematoxylin and eosin according to the technique of Bancroft \& Gamble (2008). The obtained sections were investigated under bright field light microscope and photographed.

\section{Immunohistochemical staining technique:}

Immunohistochemical labeling of Glial Fibrillary Acidic Protein (GFAP): The de-paraffinized $5 \mu \mathrm{m}$ sections of cerebellum on charged glass slides were used for immunohistochemical demonstration of GFAP using avidin-biotin-complex (ABC) immuno-peroxidase technique. The cerebellar sections were incubated in $\mathrm{H}_{2} \mathrm{O}_{2}$ for $10 \mathrm{~min}$, and then incubated with the primary anti-GFAP antibody at 1:100 dilutions for $20 \mathrm{~min}$ $25^{\circ} \mathrm{C}$. The primary antibody used was a mouse monoclonal antibody (GFAP) Ab-1 (Clone GA-5), specific to astrocytes purchased from Lab Vision Corporation, Medico Co., Egypt (Cat. \#MS-280-B0). The slides were rinsed in phosphate buffer then incubated with the secondary anti-mouse antibodies universal kits obtained from Zymed Corporation. Staining was completed by incubation with substrate chromogen DAB $(3,30$ Diaminobenzidine) for 5-10 min which resulted in browncolored precipitate at the antigen sites and Mayer's Hematoxylin was used as a counter stain. 
Immunohistochemical labeling of synaptophysin: The deparaffinized $6-\mu \mathrm{m}$ sections of cerebella were incubated with rabbit polyclonal primary antibody; Synaptophysin antibody (PA5-27286, Thermo Scientific, USA) at 1:400 dilution for 20 $\mathrm{h}$, in a moist chamber at $4{ }^{\circ} \mathrm{C}$. Binding of primary antibody was demonstrated using Thermo Scientific Super Picture ${ }^{\mathrm{TM}}$ Polymer Detection Kit. The activity of Synaptophysin expression in cerebellar cortex was determined.

The immune-histochemical prepared slides were examined, microphotographed using an Axioscop 2 plus microscope (Zeiss, Germany) with a Leica DFC 320 digital camera (Leica, Germany).

\section{Serum analysis:}

Estimation of serum antioxidants (CAT, SOD and GSH): Serum catalase (CAT) level was determined spectrophotometrically by the method of Koroliuk et al. (1988). Determination of the superoxide dismutase (SOD) activity was calculated according to the manufacturer's instruction (Ransod ${ }^{\circledR}$-Randox Lab, Antrim, UK) and expressed as U/mL. Reduced glutathione (GSH) activity was determined using a GSH assay kit (Randox Lab., Ltd., UK) according to the protocol of Ellman (1959).

Estimation of lipid peroxidation (malondialdehyde) (MDA): Malondialdehyde levels were measured in serum using the thiobarbituric acid reaction method of Placer et al. (1966).

Measurement of serum serotonin and glutamate: The serum serotonin levels were measured using a commercial enzyme immunoassay kit (Immuno-Biological Laboratories, Inc. IBL - Minneapolis, USA). Serum glutamate concentration was assayed by means of Glutamate Assay Kit (Abnova, Taipei City, Taiwan) following the manufacturer's protocol specifications.

Tissue analysis: The serum serotonin levels were measured using a commercial enzyme immunoassay kit (ImmunoBiological Laboratories, Inc.-IBL-Minneapolis, USA). Serum glutamate concentration was assayed by means of Glutamate Assay Kit (Abnova, Taipei City, Taiwan) following the manufacturer's protocol specifications.

Determination of Dopamine: Dopamine measurements in cerebellar tissue homogenate was done by using rat dopamine ELISA kit (MyBioSource, San Diego, CA, USA) by a synergy 2 Multi- Mode Reader microplate (BioTek) at $450 \mathrm{~nm}$.

Flow cytometric detection of Caspase-3 and B-cell lymphoma-2 (BCl-2): Flow cytometric detection of activated caspase-3 was done in order to determine the number of apoptotic cells in the cerebellar tissue homogenate. This technique is applicable where the fluorochrome is directly linked to the primary antibody (PE and FITC conjugate). The cells were prepared appropriately. The cell suspension was adjusted to a concentration of $1 \times 106$ cell $/ \mathrm{ml}$ in phosphate buffered saline and 1\% BSA. Aliquot of $100 \mu \mathrm{L}$ of cell suspension was separated into test tubes. The antibody (FITC rabbit anti-active caspase-3, solid as, material
No. 559341, catalog No. 554714, from BD Pharmingen) was added to $10 \mu \mathrm{L}$ for each sample, mixed well and then incubated at $250^{\circ} \mathrm{C}$ for $30 \mathrm{~min}$ followed by washing in $2 \mathrm{ml}$ of PBS/BSA then centrifuged at $1500 \mathrm{rpm}$ for about $5 \mathrm{~min}$ and the resulting supernatant was discard. The cells were re- suspended in 0.2 $\mathrm{ml}$ of PBS/BSA if required. The data was obtained by flow cytometry. This technique was done in the Mansoura University Hospital using flow activated cell sorter (FACS) Calibur Flow Cytometer (Becton Dickin-son, Sunnyvale, CA, USA) equipped with a compact air-cooled low power $15 \mathrm{~mW}$ Argon ion laser beam $(488 \mathrm{~nm})$.

B cell lymphoma-2 (BCL-2): Flow cytometric analysis of cytoplasmic bcl-2 expression was done using a Coulter EPICS XL apparatus and EXPO 32 software (Beckman Coulter, Miami, FL, USA) according to the method of Newell et al. (2003). Briefly, the cerebellar tissue cells were bulk-lysed using buffered $\mathrm{NH}_{4} \mathrm{Cl}$. The cells were next incubated with anti-bcl-2 antibody (PE-labelled clone 6C8; Pharmingen, San Diego, CA,USA) for $20 \mathrm{~min}$ in the dark, washed and then put in phosphate buffered saline with $1 \%$ paraformaldehyde before analysis. The bcl-2 relative fluorescence values (RFV) for the gated populations of interest were calculated as the mean channel value for bcl-2stained cells minus the mean channel value for isotype control stained cells, divided by the mean isotype control value.

\section{Statistical analysis}

Data are expressed as mean \pm standard error $\{n=5$ per group $\}$ statistical analysis one way ANOVA followed by post hoc test means in the same row with different superscript $\left(^{*}\right)$ are significantly different when $\mathrm{p}<0.05^{*}$ significant at value $<0.05$, ${ }^{* *}$ significant at $\mathrm{p}$-value $<0.01$ and ${ }^{* * *}$ significant $\mathrm{p}$ value $<0.001$ in comparison with control.

\section{RESULTS}

\section{Body weight changes}

The results of the present work revealed that, the mean body weight of melatonin supplemented group displayed nonsignificant change with control however, the deltamethrin treated mother's rats and their offspring showed highly significant decrease $(\mathrm{P}<0.001)$. In deltamethrin treated rats that followed by supplementation with melatonin either for mothers and their offspring, the mean body weight showed nonsignificant $(\mathrm{P}>0.05)$ changes in comparing with control (Table 1 and Figures 1 and 2).

\section{Histological observations}

In control and melatonin supplemented mother's rats (Figures $3 \mathrm{~A}-3 \mathrm{D})$ and their offspring (Figures 4A-4D), the sections of the cerebellum showed the normal characteristic structure of the cerebellum and its layers; the outer cerebellar cortex (gray matter) and inner medulla (white matter). The cerebellar cortex presented three layers; the outer molecular, intermediate Purkinje and inner granular layers. The molecular layer showed

Table 1: The body weight changes ( $\mathrm{g}$ ) of mother rats and their offspring in different studied groups.

\begin{tabular}{|c|c|c|c|c|}
\hline Group N=6 & Control & Melatonin & Deltamethrin & Deltamethrin \& Melatonin \\
\hline Mother & $202.75 \pm 2.08$ & $204.4 \pm 3.6$ & $173.1667 \pm 2.322^{* * *}$ & $200.9167 \pm 2.925$ \\
\hline 21 Days & $34.9167 \pm 1.89$ & $33.5 \pm 2.477$ & $24.1667 \pm 1.195^{* * *}$ & $33.1667 \pm 1.96$ \\
\hline
\end{tabular}




\section{Mother}

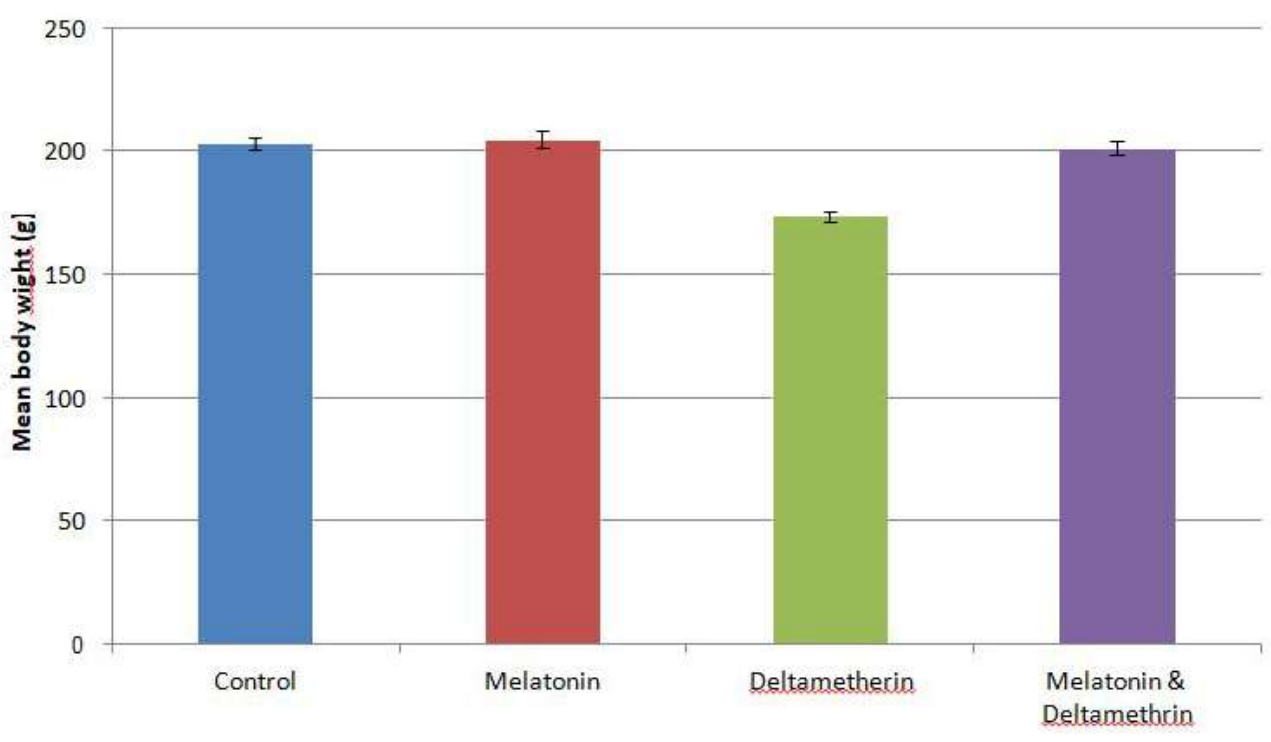

Figure 1: Illustrating the body weight changes of mother's rats among the different studied groups.

\section{Day}

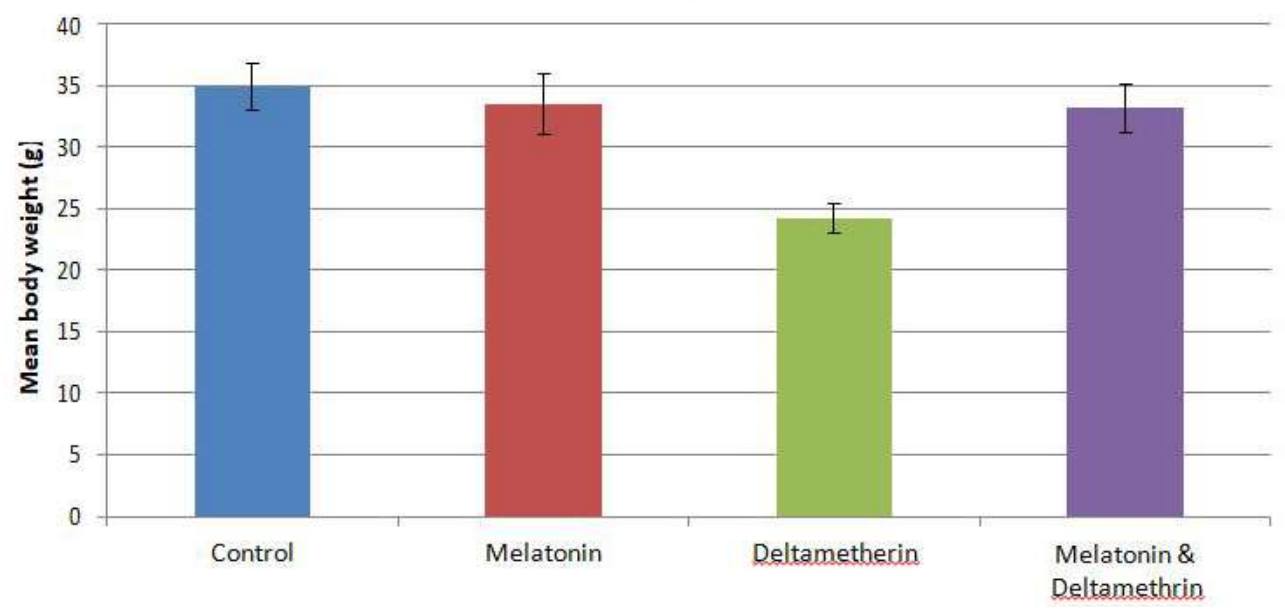

Figure 2: Illustrating the body weight changes of $21^{\text {th }}$ day's old rats among the different studied groups.

sparsely distributed stellate and basket cells in addition to axons and dendrites as well as capillaries that penetrate deep into this layer. The Purkinje cell layer represented by one cell thick of a monolayer of flask shaped uniformly arranged cells between the molecular and granular layers with deeply stained basophilic nuclei. The granular layer is well defined and darkly stained due to the presence of densely packed rounded and oval cells of variable sizes.

In deltamethrin exposed mother's rats (Figures $3 \mathrm{E}$ and $3 \mathrm{~F}$ ), the cerebellar cortex presented the three layers with apparently partial loss and degenerative Purkinje cells, cellular hypertrophy in the molecular and granular layers and deep-staining pyknotic granule cells. Also, little cytoplasmic vacuoles were noticed in some granular and Purkinje cells. On the other side, the cerebellar cortex of $21^{\text {th }}$ days old rats induced with deltamethrin displayed multiple pyknosis of Purkinje cells and granular cells with scattered vacuoles especially in the granular layer (Figures 4E and 4F)).
In deltamethrin-treated group of mothers (Figures $3 \mathrm{G}$ and $3 \mathrm{H}$ )) and their offspring (Figures $4 \mathrm{G}$ and $4 \mathrm{H}$ )) that supplemented with melatonin, the cerebellar cortex displayed obvious recovery in their histological pattern in spite of little pyknotic Purkinje still found in the cerebellar cortex of mothers.

\section{Immunohistochemical observation}

Immunohistochemical localization of Glial fibrillary acidic protein (GFAP): The sections of cerebellar cortex of control and melatonin supplemented mother's rats (Figures 5A and 5B) and their offspring (Figures 6A and 6B)) were expressed weak to moderate immunoreactivity for glial fibrillary acidic protein (GFAP). In deltamethrin induced mothers rats (Figure 5C), an intensive positive immune expression for GFAP was obviously appeared all-over the section. In $21^{\text {th }}$ day's old rats that exposed to deltamethrin through the placenta and lactation, the cerebellar GFAP immune- reactivity was apparently stronger than that of control (Figure 6C). Indeltamethrin treated mother's rats (Figure 

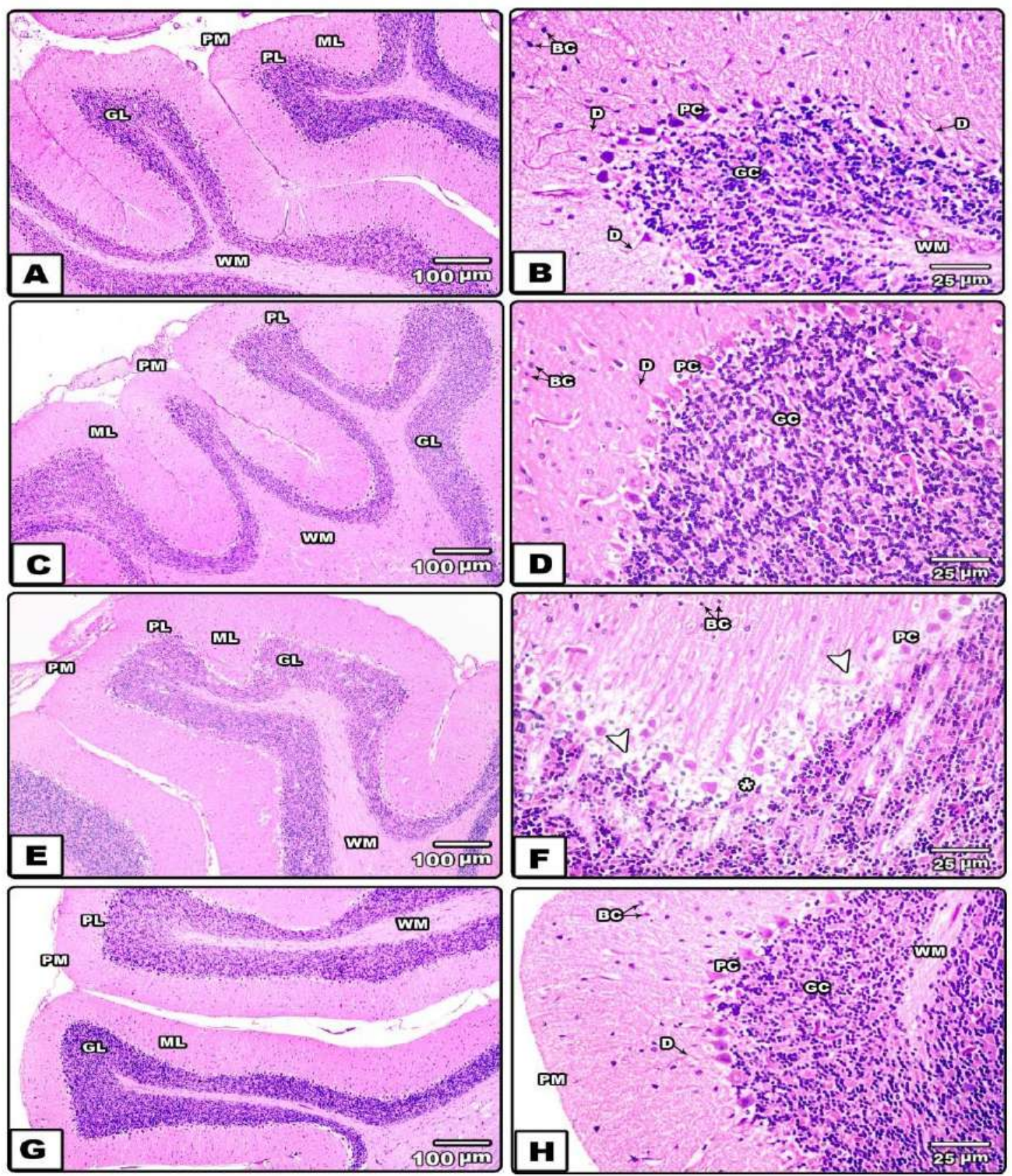

Abbreviations: BC: Basket Cell; D: Dendrite, PC:Purkinje Cell; GC:Granuler Cells; PM: Pia Matter; ML: Molecular Layer; GL: Granuler Layer; WM: White Matter.

Figure 3: Photomicrographofhistologicalsectionsthroughthecerebllumof mothersratsofdifferentstudiedgroups. Control group (A\&B), melatoningr oup $(\mathrm{C} \& \mathrm{D})$, deltamethrintreatedgroup $(\mathrm{E} \& \mathrm{~F})$ and deltamethrin\&melatoningroup $(\mathrm{G} \& \mathrm{H})$. In control and melatonin groups, thecerebellarsectionsapp earwith normal histologicalarchitecture.Indeltamethrin treated mothers rats the cerebellar sections showingobvoiusdegeneratedPukinjecell(arrow head), scattered vacuoles(star),lowdensityandobviouspyknosisin granular and basket cells. In deltamethrin \&melatoninratsthecerebellarsections showing remarkable amelioration that tend to be more or less as control $\{\mathrm{H} \& \mathrm{E}, \mathrm{A}, \mathrm{C}, \mathrm{E} \& \mathrm{G}(\mathrm{X}=100), \mathrm{B}, \mathrm{D}, \mathrm{F} \& \mathrm{H}(\mathrm{X}=250)\}$.

5D) and their offspring (Figure 6D) post supplemented with melatonin, the cerebellar sections revealed moderate immune expression for GFAP.

As a general aspect the GFAP immunoreactivity was more localized in the intermediate cells of molecular layer and granular layer however for both mother and their offspring.

Immunohistochemical localization of Synaptophysin (SYN) in cerebellar tissue: In control and melatonin mother's rats, the SYP immunoreactivity was strongly or moderately detected in the various layers of cerebellar cortex (Figure 7A and 7B) whilein deltamethrin treated mother rats such activity was markedly decreased and also appeared in form of clusters around the neurons in some area of the sections (Figure 7C). On the other side, deltamethrin treated mothers post supplemented with melatonin a remarkable restore in the SYN immunoreactivity was noticed all-over the cerebellar layers that more or less similar to control (Figure 7D).

In control and melatonin 21 days' old rats, the cerebellar immunoreactivity of syanptophysin was appeared stronger 

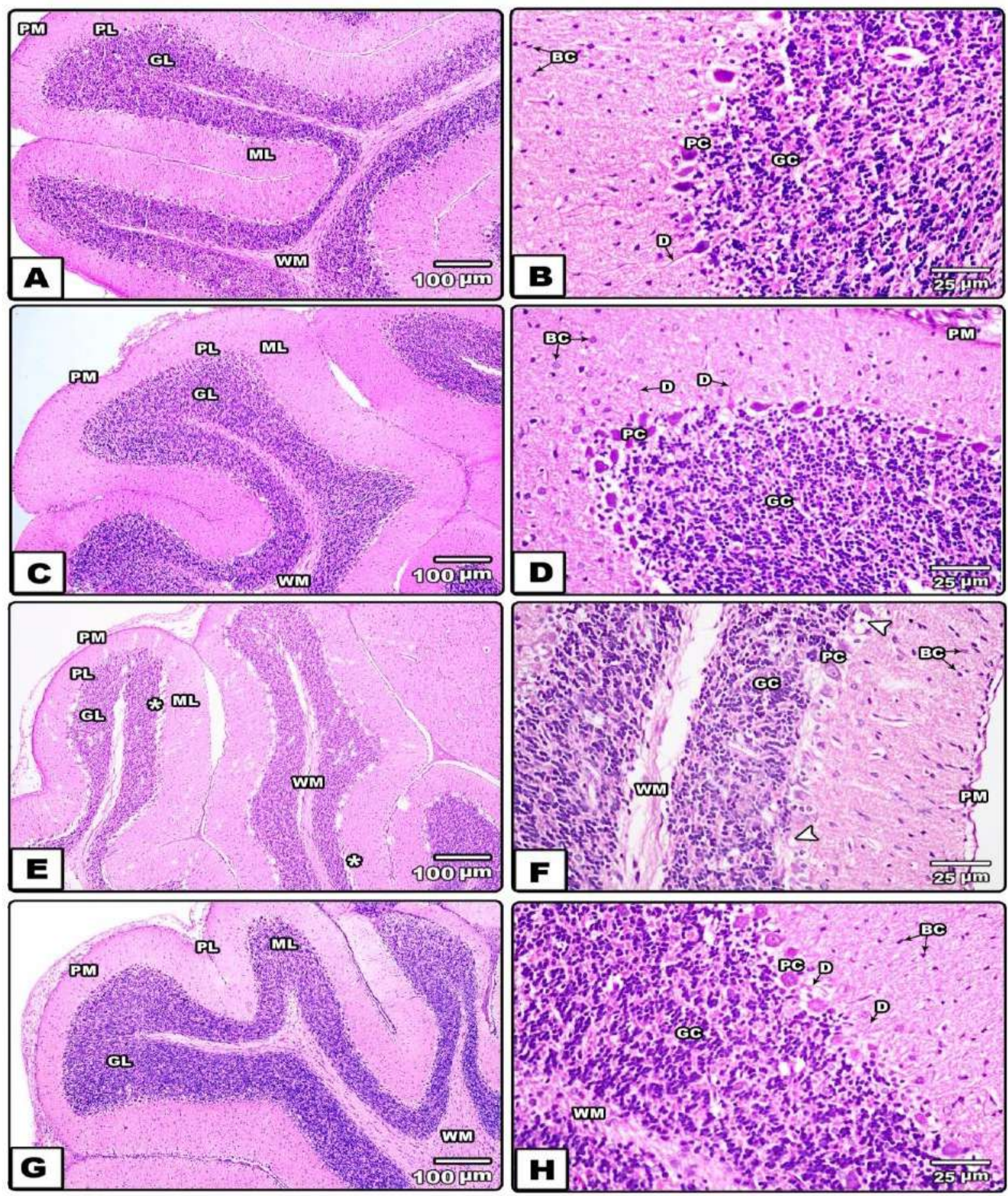

Abbreviations: BC: Basket Cell; D: Dendrite, PC:Purkinje Cell; GC:Granuler Cells; PM: Pia Matter; ML: Molecular Layer; GL: Granuler Layer; WM: White Matter.

Figure 4: Photomicrograph ofhistologicalsectionsthroughthecerebllumof21daysold rats ofdifferent studiedgroups. Control group (A\&B), melato ningroup $(\mathrm{C} \& \mathrm{D})$,deltamethrintreatedgroup $(\mathrm{E} \& \mathrm{~F})$ and deltamethrin\&melatoningroup $(\mathrm{G} \& \mathrm{H})$.In control and melatoningroups, thecerebellarsections appearwith normal histologicalarchitecture.Indeltamethrintreatedoffspringthecerebellarsections showingobvoiusdegeneratedPukinjecell(arrowhea d),scatteredvacuoles (star), lowdensityandobviouspyknosisingranularandbasketcells. In deltamethrin \&melatonin offspring the cerebellar sections showing remarkable recovery in their strucuture that tend tobe more or less as control. $\{\mathrm{H} \& \mathrm{E}, \mathrm{A}, \mathrm{C}, \mathrm{E} \& \mathrm{G}(\mathrm{X}=100), \mathrm{B}, \mathrm{D}, \mathrm{F} \& \mathrm{H}(\mathrm{X}=250)\}$

or intensive than those of their mothers (Figure $8 \mathrm{~A}$ and $8 \mathrm{~B}$ ), however, a weak immune reaction for SYN was appeared in the cerebellar cortex of deltamethrin induced offspring, also it is appeared in form of disclosed large coarse pericellular reactivity (Figure 8C). In deltamethrin treated offspring that ameliorated with melatonin, the cerebellar cortex displayed a moderate to strong expression for SYN (Figure 8D).

Generally the immune-reactivity of SYN was more localized in the granular and molecular layer of cerebellar cortex but the intensity of expression was prominent in offspring rather than mother. 


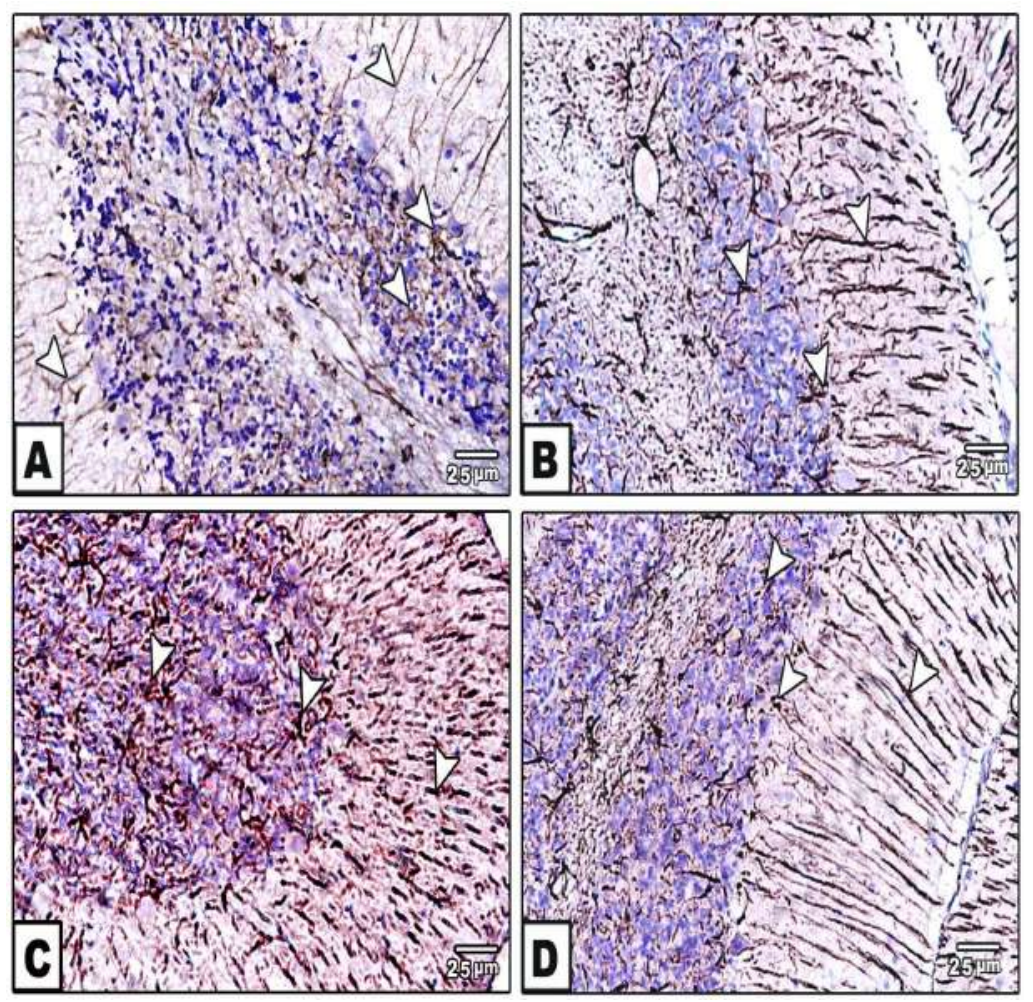

The arrows referred to the degree of GFAP immune-reactivity that more localized in the intermediate cells of ML and granular cells of GL.

Figure 5: Photomicrograph of embedded paraffin sections of cerebellar cortex of mother Albino rats stained with GFAP antibody of control (A), melatonin (B), deltamethrin (C), deltamethrin \&melatonin (D). Note: a weak to moderate immune expression in the cerebellar cortex of control and melatonin groups but a strong positive immune expression appears in the cerebellar cortex of deltamethrin treated rats if compared with other studied groups (X: 250).
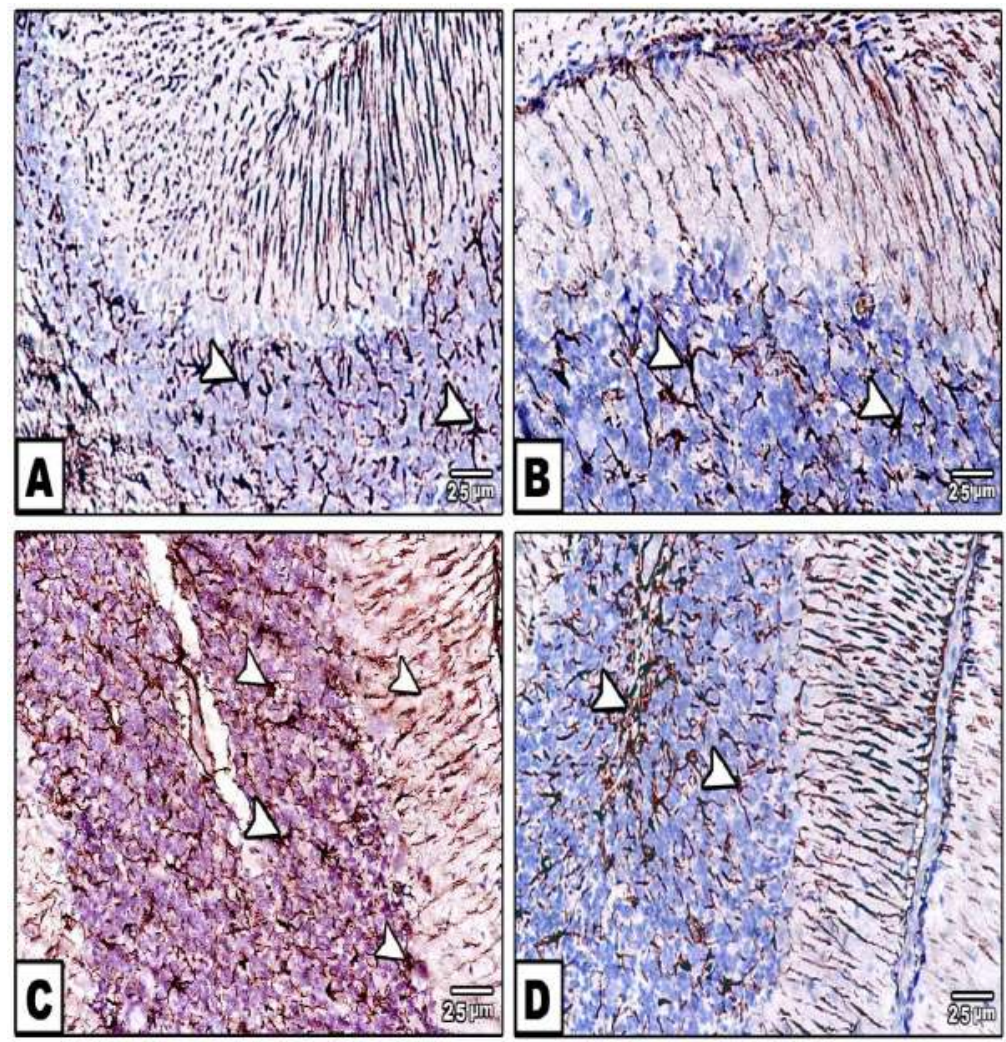

The arrows referred to the degree of GFAP immune expression that more localized in the intermediate cells of ML and granular cells of GL.

Figure 6: Photomicrograph of embedded paraffin sections of cerebellar cortex of 21day old rats stained with GFAP antibody of control (A), melatonin (B), deltamethrin (C), deltamethrin \&melatonin (D). Note: a weak immune expression in the cerebellar cortex of control and melatonin groups but a moderate to strong positive immune expression appears in the cerebellar cortex of offspring which their mothers exposed to deltamethrin if compared with other studied groups (X: 250). 

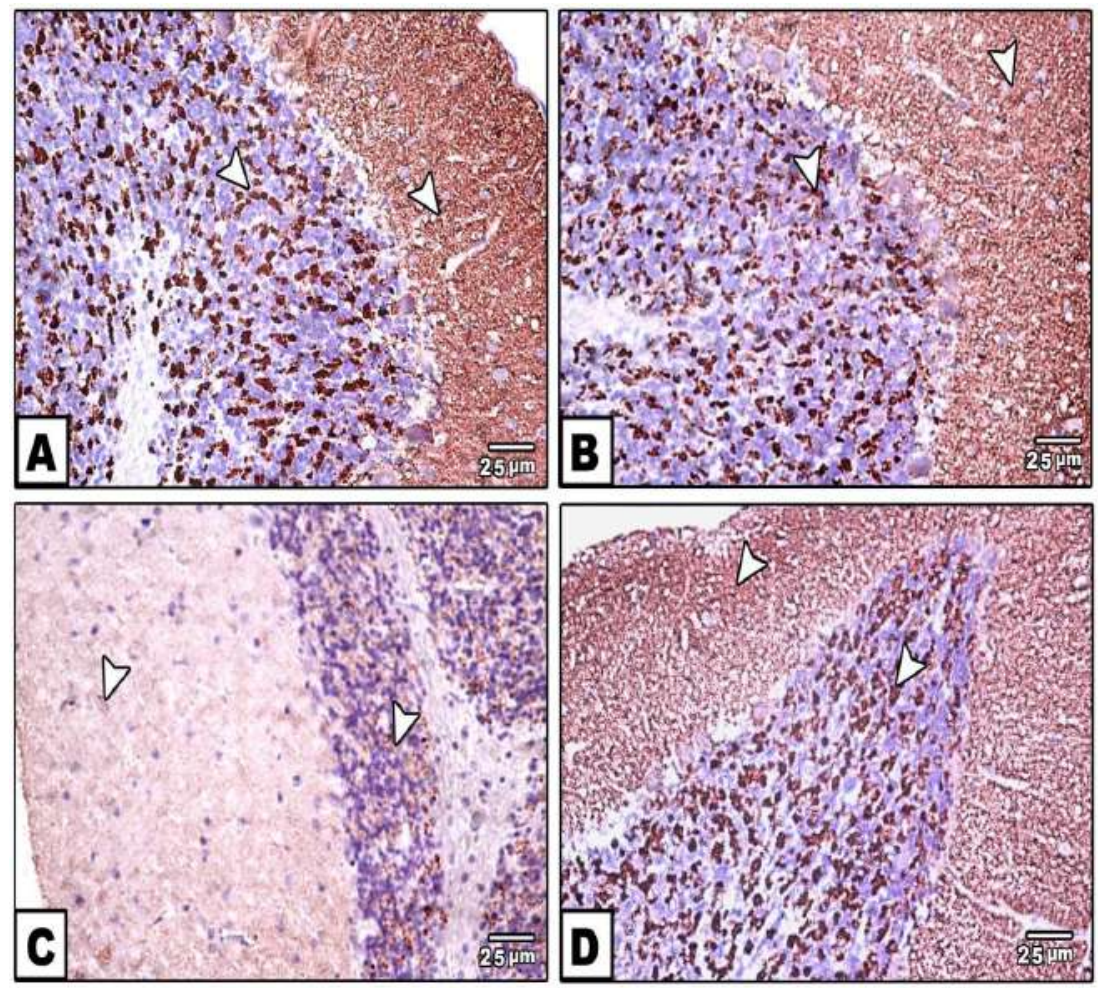

The arrows referred to the degree of synaptophysin immune expression that more localized in the basket cells of ML and granular cells of GL.

Figure 7: Photomicrograph of embedded paraffin sections of cerebellar cortex of mother Albino rats stained with synaptophysin antibody of control (A), melatonin (B), deltamethrin (C), deltamethrin \&melatonin (D). Note: a strong immune expression in the cerebellar cortex of control and melatonin groups while; a very weak immune expression appears in the cerebellar cortexofdeltamethrininducedmothersratsifcomparedwith otherstudied groups(X: 250)
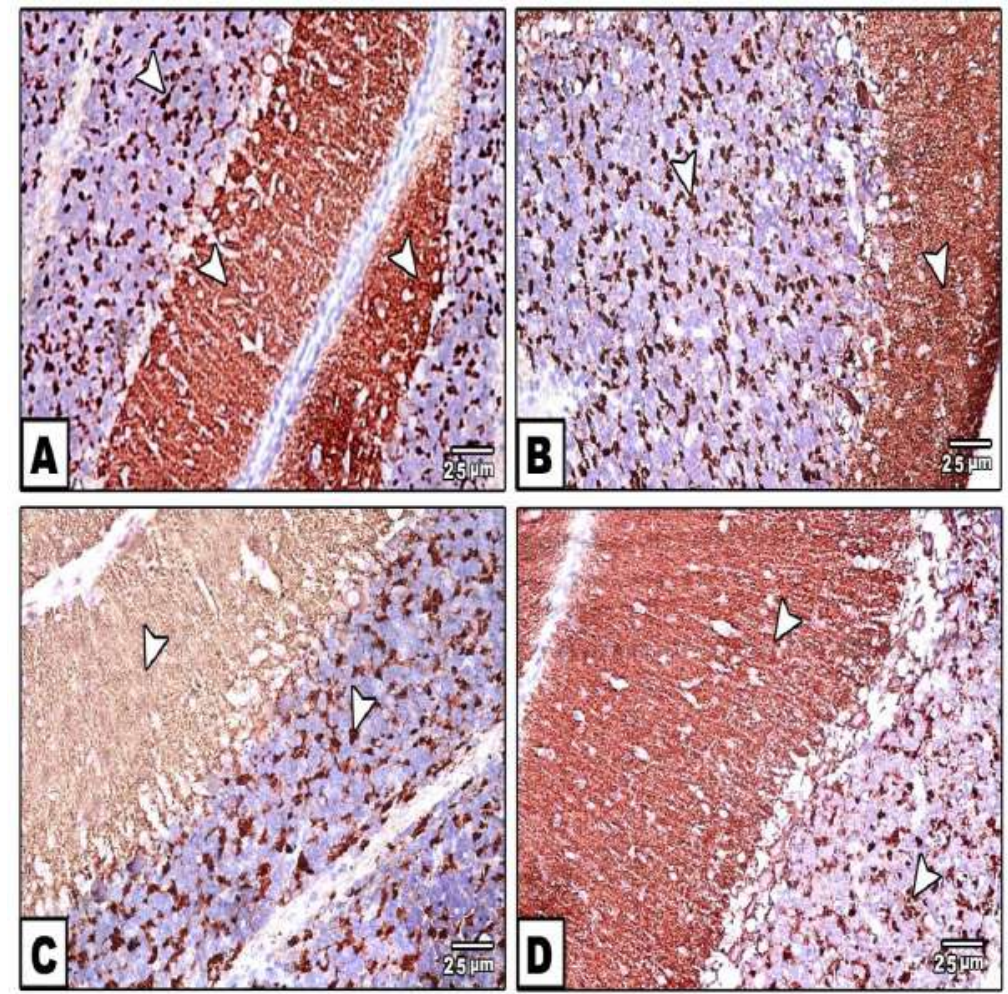

The arrows referred to the degree of synaptophysin immune reaction that more confined to the basket cells of ML and granular cells of GL.

Figure 8: Photomicrograph of embedded paraffin sections of cerebellar cortex of 21 days old rats stained with synaptophysin antibody of control (A), melatonin (B), deltamethrin (C), deltamethrin \&melatonin (D). Note: a strong immune expression in the cerebellar cortex of control and melatonin groups while; a weak to moderate immune expression appears in the cerebellar cortex of deltamethrin induced rats if compared with other studied groups (X: 250). 


\section{Serum analysis}

Antioxidants (SOD, CAT and GSH): In mother's rats and their offspring that supplemented with melatonin, the level of SOD, CAT and GSH showed non-significant change with control. In deltamethrin exposed mothers rats and their offspring, the level of SOD showed a remarkable significant decrease $(\mathrm{P}<0.001)$ if compared with control. Post-treatment of mothers' rats with melatonin was ameliorated this deltamethrin-induced changes in the SOD enzyme in spite of a low significant decrease still present in mothers (Table 2 and Figures 9 and 10). A highly significant decrease $(\mathrm{P}<0.001)$ for serum catalase was recorded in the deltamethrin-treated mothers and their offspring. Moreover, post-treatment of mothers with melatonin was ameliorated such change in the catalase enzyme induced by deltamethrin notably in offspring rather than mother which still display low significant decline with control (Table 3 and Figures 11 and 12).

In deltamethrin-treated mothers, the serum level of reduced

Table 2: The mean value of serum SOD (U/L) among the different studied groups of mother's rats and their offspring.

\begin{tabular}{|l|l|l|l|l|}
\hline SOD & Control & Melatonin & Deltamethrin & Deltamethrin \& Melatonin \\
\hline Mother & $0.293 \pm 0.008$ & $0.2737 \pm 0.006$ & $0.0932 \pm 0.004^{* * *}$ & $0.259 \pm 0.009^{*}$ \\
\hline 21 Days & $0.2235 \pm 0.008$ & $0.2053 \pm 0.008$ & $0.0912 \pm 0.003^{* * *}$ & $0.1852 \pm 0.004^{* *}$ \\
\hline
\end{tabular}

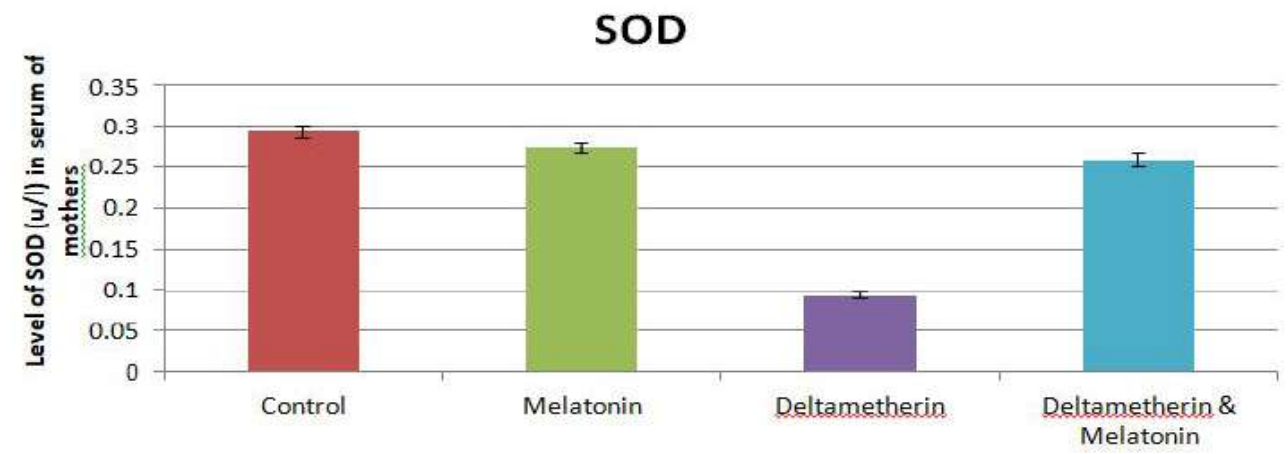

Figure 9: Illustrating the mean value of serum SOD among the different studied groups of mothers rats.

\section{SOD}

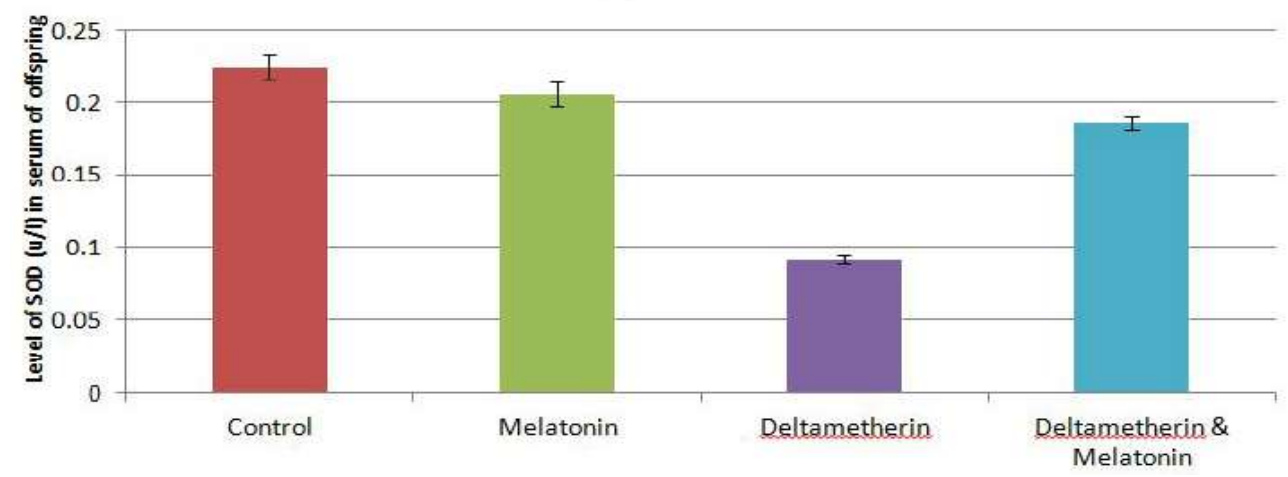

Figure 10: Illustrating the mean value of serum SOD among the different studied groups of 21 days old rats.

Table 3: The mean value of serum CAT $(\mathrm{ng} / \mathrm{ml})$ among the different studied groups of mother's rats and their offspring.

\begin{tabular}{|l|l|l|l|l|}
\hline CAT & Control & Melatonin & Deltamethrin & Deltamethrin \& Melatonin \\
\hline Mother & $0.2503 \pm 0.012$ & $0.2385 \pm 0.02$ & $0.1023 \pm 0.006^{* * *}$ & $0.2012 \pm 0.013$ \\
\hline 21 Days & $0.2988 \pm 0.013$ & $0.2678 \pm 0.011$ & $0.1238 \pm 0.010^{* * *}$ & $0.239 \pm 0.011$ \\
\hline
\end{tabular}

\section{CAT}

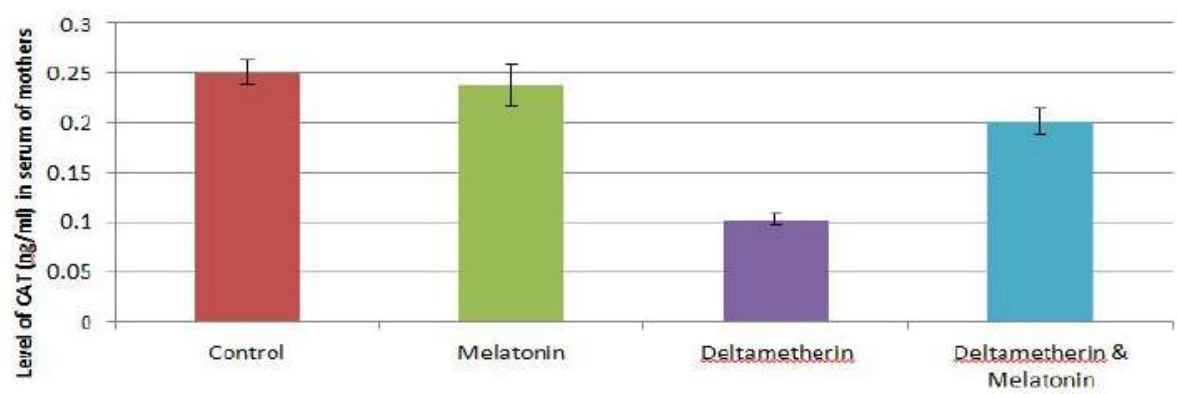

Figure 11: Illustrating the mean value of serum CAT among the different studied groups of mothers rats. 
glutathione (GSH)was displayed a high significant decrease $(\mathrm{P}<0.001)$ while their offspring displayed low significant decrease if compared with control and melatonin groups. On the other side, the post-treatment of mothers with melatonin was attenuated such change in the GSH enzyme but still exhibited low significant decrease while their offspring displayed nonsignificant with control (Table 4 and Figures 13 and 14).

Malondialdehyde (MDA): The obtained result of the current work revealed no significant change in the serum level of MDA for melatonin supplemented mothers rats if compared with control, however, such levels showed high significant increase in deltamethrin treated mother's rats and their offspring $(\mathrm{P}<0.001)$ if compared with control. On the other side, the post-treatment of mothers with melatonin was attenuated such change in that more or less similar to that of control (Table 5 and Figures 15 and 16).

Serotonin and glutamate: In comparing with control and melatonin group, the serum levels of serotonin and glutamate in deltamethrin treated mothers rats showed a high significant decrease $(\mathrm{P}<0.001)$ but their offspring showed low significant decrease $(\mathrm{P}<0.05)$. In deltamethrin and melatonin group of mothers rats the levels of serotonin and glutamate showed remarkable increase but still showing low significant decrease if compared with control. Furthermore, the serum levels of glutamate and serotonin showed remarkable amelioration in offspring of mothers that treated with deltamethrin and supplemented with melatonin (Tables 6 and 7 and Figures 17-20).

\section{CAT}

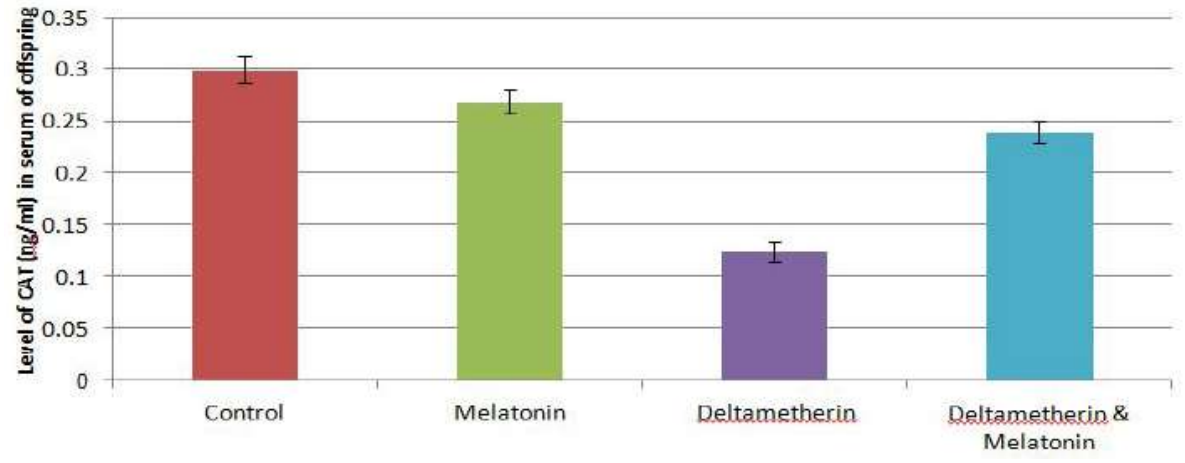

Figure 12: Illustrating the mean value of serum CAT among the different studied groups of 21 days old rats.

Table 4: The mean value of serum GSH (ng $/ \mathrm{ml}$ ) among the different studied groups of mother's rats and their offspring.

\begin{tabular}{|l|l|l|l|l|}
\hline GSH & Control & Melatonin & Deltamethrin & Deltamethrin \& Melatonin \\
\hline Mother & $0.3858 \pm 0.007$ & $0.3343 \pm 0.02$ & $0.091 \pm 0.02^{* * *}$ & $0.317 \pm 0.03^{*}$ \\
\hline 21 Days & $0.3043 \pm 0.016$ & $0.2713 \pm 0.006$ & $0.1807 \pm 0.006^{*}$ & $0.259 \pm 0.009$ \\
\hline
\end{tabular}

\section{GSH}

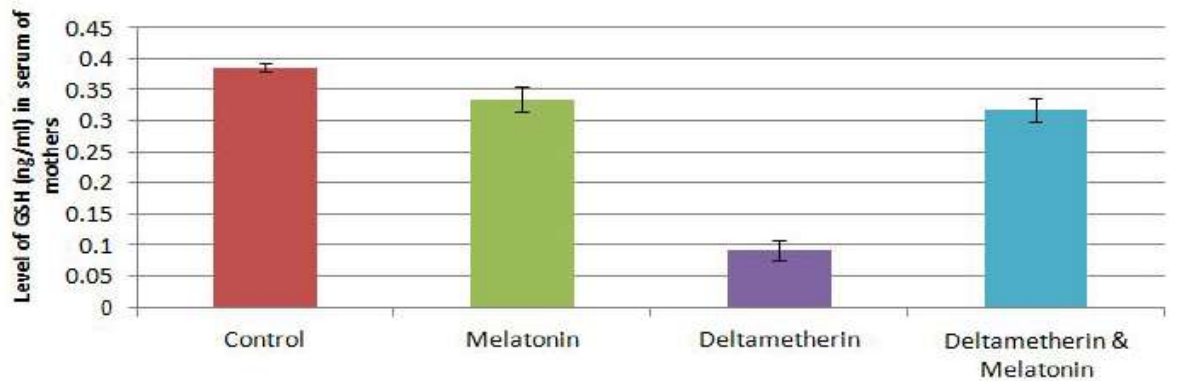

Figure 13: Illustrating the mean value of serum GSH among the different studied groups of mothers rats.

\section{GSH}

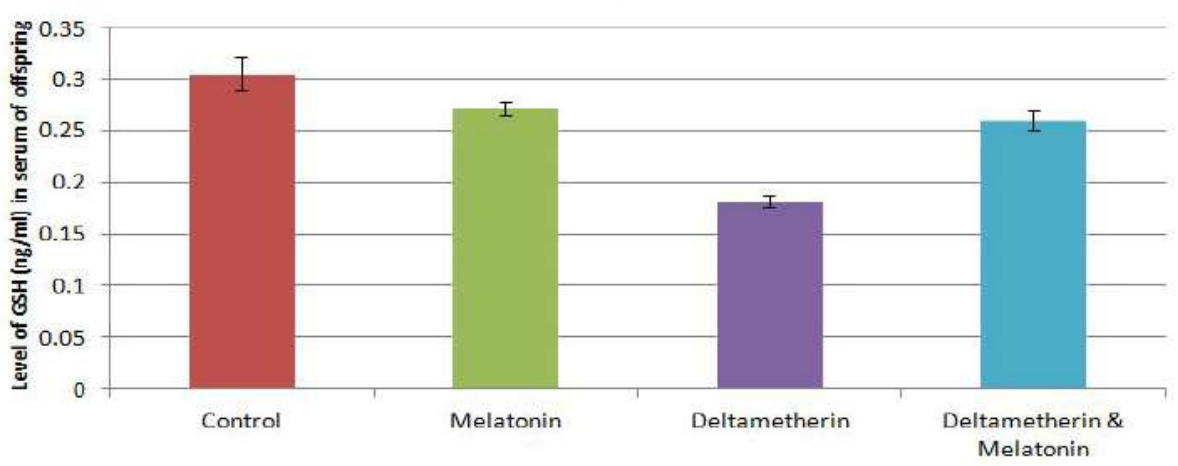

Figure 14: Illustrating the mean value of serum GSH among the different studied groups of 21 days old rats. 
Table 5: The mean value of serum MDA ( $\mathrm{nmo} / \mathrm{ml}$ ) among the different studied groups of mother's rats and their offspring.

\begin{tabular}{|l|l|l|l|l|}
\hline MDA & Control & Melatonin & Deltametherin & Deltametherin \& Melatonin \\
\hline Mother & $0.25 \pm 0.014$ & $0.3 \pm 0.008$ & $0.54 \pm 0.009^{* * *}$ & $0.316 \pm 0.02^{*}$ \\
\hline 21 Days & $0.1697 \pm 0.005$ & $0.195 \pm 0.003$ & $0.3863 \pm 0.011^{* * *}$ & $0.2107 \pm 0.01^{*}$ \\
\hline
\end{tabular}

\section{MDA}

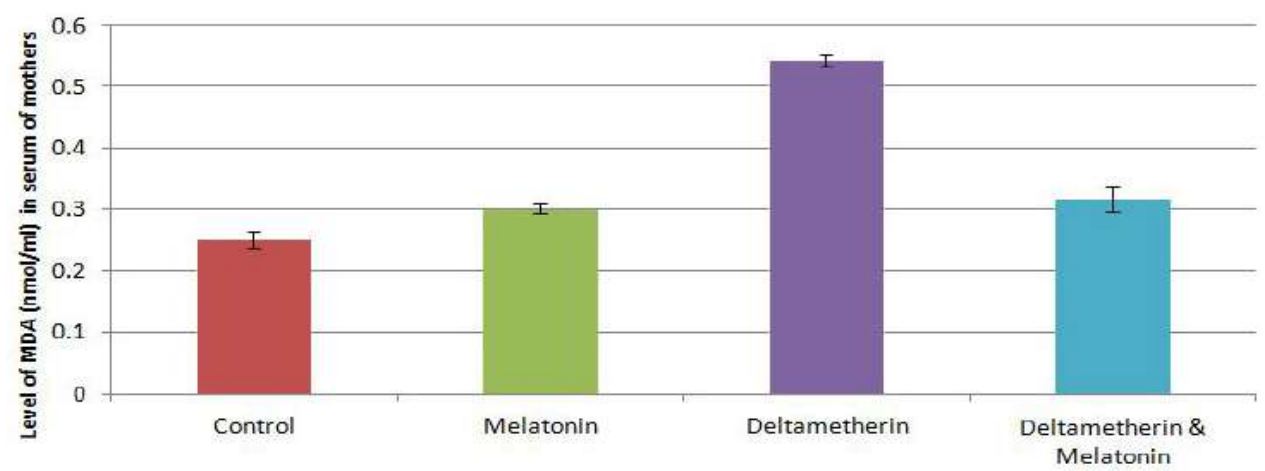

Figure 15: Illustrating the mean value of serum MDA among the different studied groups of mothers rats.

\section{MDA}

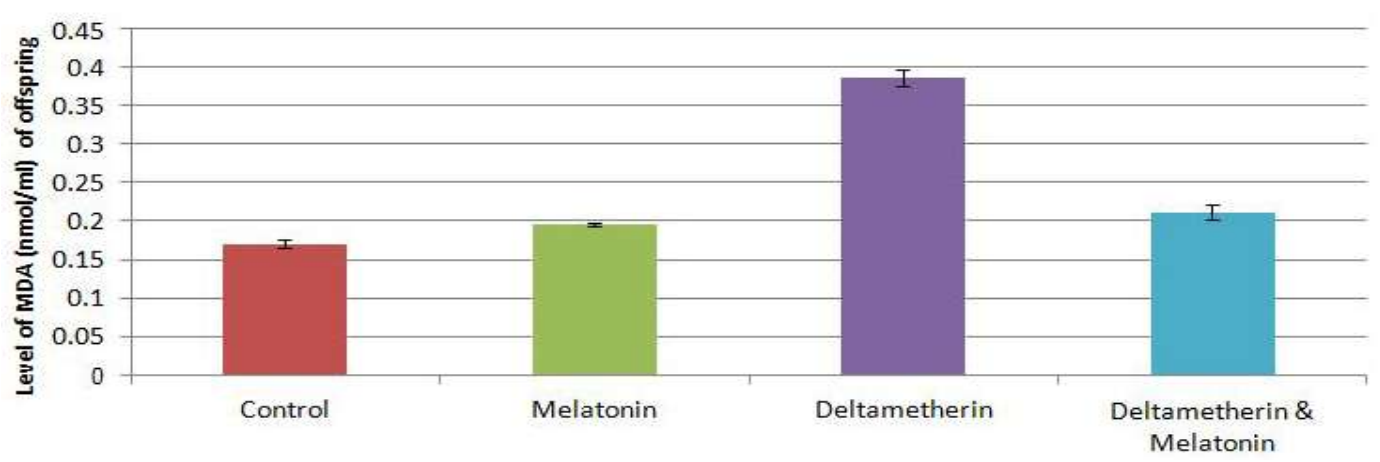

Figure 16: Illustrating the mean value of serum MDA among the different studied groups of 21 days old rats.

Table 6: The mean value of serum serotonin $(\mathrm{ng} / \mathrm{ml})$ among the different studied groups of rats and their offspring.

\begin{tabular}{|l|l|l|l|l|}
\hline Serotonin & Control & Melatonin & Deltametherin & Deltametherin \& Melatonin \\
\hline Mother & $0.315 \pm 0.014$ & $0.2768 \pm 0.11$ & $0.115 \pm 0.015^{* * *}$ & $0.2348 \pm 0.012^{* *}$ \\
\hline 21 Days & $0.3082 \pm 0.007$ & $0.2852 \pm 0.004$ & $0.1478 \pm 0.008^{* * *}$ & $0.2843 \pm 0.009$ \\
\hline
\end{tabular}

Table 7: The mean value of serum glutamate $(\mathrm{Ug} / \mathrm{ml})$ among the different studied groups of mother's rats and their offspring.

\begin{tabular}{|l|l|l|l|l|}
\hline Glutamate & Control & Melatonin & Deltametherin & Deltametherin \& Melatonin \\
\hline Mother & $0.3465 \pm 0.017$ & $0.301 \pm 0.022$ & $0.1375 \pm 0.004^{* * *}$ & $0.314 \pm 0.006$ \\
\hline 21 Days & $0.3303 \pm 0.01$ & $0.3073 \pm 0.011$ & $0.1618 \pm 0.004^{* * *}$ & $0.2857 \pm 0.005^{*}$ \\
\hline
\end{tabular}

\section{serotonin}

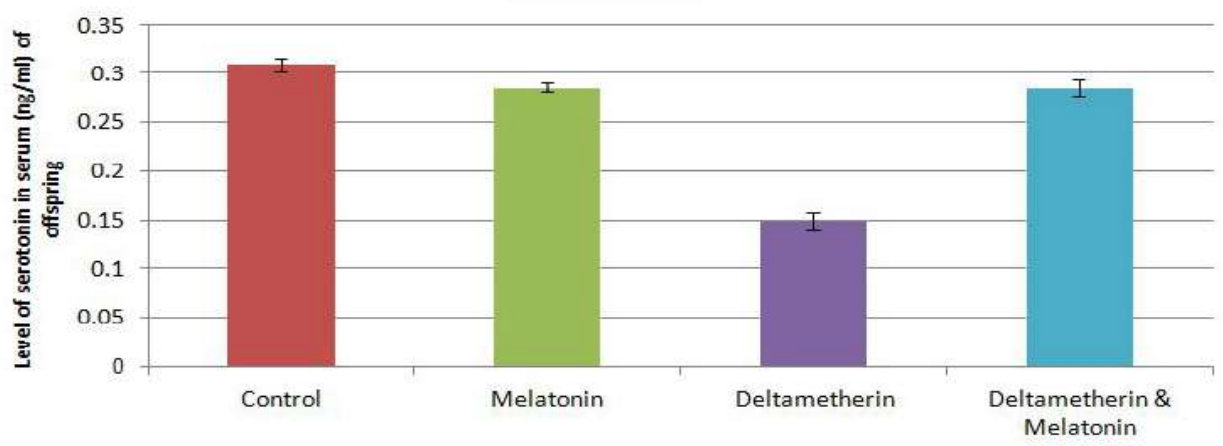

Figure 17: Illustrating the mean value of serum serotonin among the different studied groups of mothers rats. 


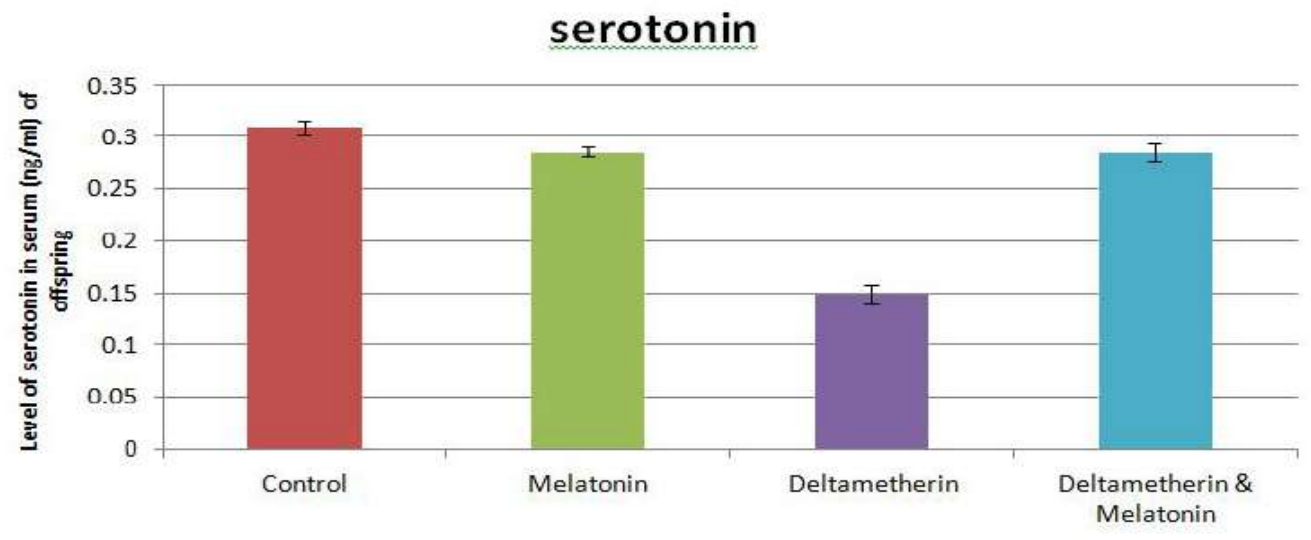

Figure 18: Illustrating the mean value of serum serotonin among the different studied groups of 21 days old rats.

\section{Glutamate}

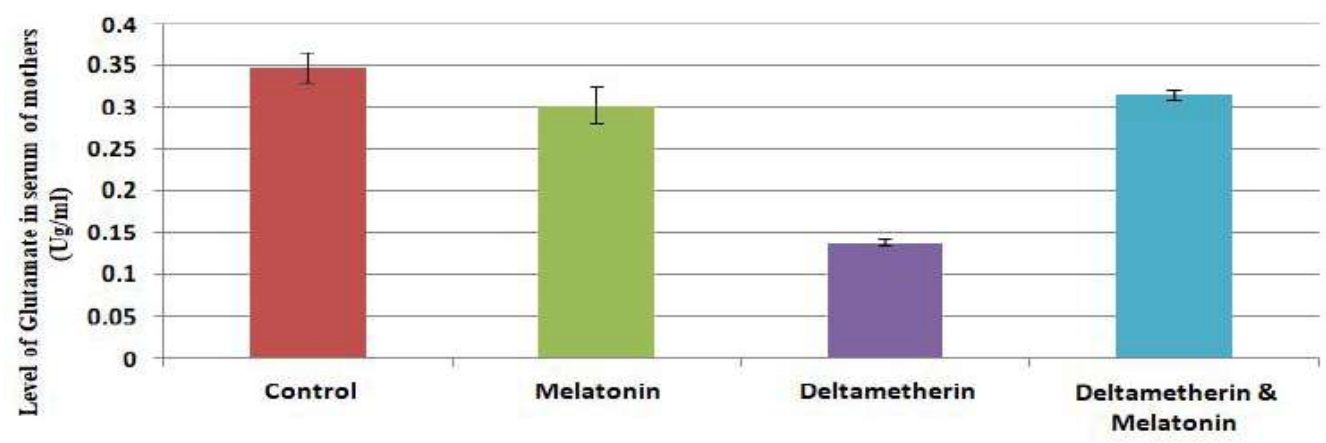

Figure 19: Illustrating the mean value of serum serotonin among the different studied groups of 21 days.

\section{Glutamate}

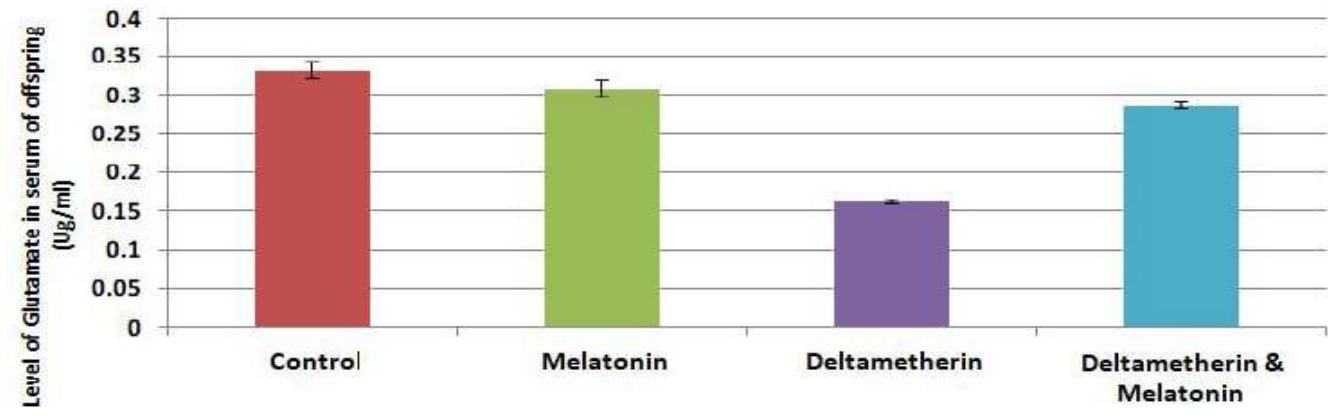

Figure 20: Illustrating the mean value of serum glutamate among the different studied groups of 21 days.

Table 8: The mean value of eclcicrral ebrrec dopamine ( $\mathrm{ng} / \mathrm{ml})$ among the different studied groups of mother's rats and their offspring.

\begin{tabular}{|l|l|l|l|l|}
\hline Dopamine & Control & Melatonin & Deltamethrin & Deltamethrin \& Melatonin \\
\hline Mother & $0.354 \pm 0.02$ & $0.3353 \pm 0.01$ & $0.0838 \pm 0.004^{* * *}$ & $0.2615 \pm 0.02^{* *}$ \\
\hline 21 Days & $0.2907 \pm 0.007$ & $0.2735 \pm 0.013$ & $0.1705 \pm 0.008^{* * *}$ & $0.255 \pm 0.014$ \\
\hline
\end{tabular}

\section{Tissue analysis}

Dopamine activity:The cerebellar tissue homogenate of deltamethrin treated mothers rats showed high significant increase in dopamine activity $(\mathrm{P}<0.001)$ while their offspring was revealed non-significant change if compared with control. In deltamethrin group of mother rats that supplemented with melatonin the dopamine activity was ameliorated but still showing low significant $(\mathrm{P}<0.05)$ increase if compared with control (Table 8 and Figures 21 and 22).
Flow cytometry of Caspase-3 and B-cell lymphoma-2 (BCl2): In the present study, the apoptotic values in the cerebellar tissues were significantly higher $(\mathrm{P}<0.001)$ in deltamethrin treated mothers rats and their offspring if compared with control. In detail, the deltamethrin treated mothers rats and their offspring showed highly significant increase $(\mathrm{P}<0.001)$ for the mean percentage values of cerebellar caspase- 3 while their percentage values for BCL-2 was markedly revealed highly significant decrease $(\mathrm{P}<0.001)$ if compared with control and melatonin groups. On the other side, a remarkable amelioration 
in the mean percentage values either for caspase-3 and BCL-2 was recorded after supplementation of melatonin to deltamethrin treated mothers rats (Figures 23-26).

\section{DISCUSSION}

Deltamethrin is a wide spectrum neurotoxic pyrethroid insecticide either for animals and human. Its neurotoxicity mainly caused by exposure of individuals to deltamethrincontaminated air, water and food (Kim et al., 2008). Chronic exposure of pregnant mothers to deltamethrin can induce several toxic effects on their pups whereas; deltamethrin metabolites can penetrate the placenta and excreted with milk (Patro et al., 1997, Joya and Sangha, 2016).

Wang et al. (2005) reported that melatonin can rapidly penetrate the BBB after systemic supplementation and distributed throughout the different parts of brain. On other mean, melatonin has a high degree of lipophilicity and thus does not need any binding receptor for its action (Hataya et al., 2001). Other studies have indicated that melatonin has a powerful antioxidant role against oxidative stress induced by some extrinsic or intrinsic factors (Tan et al., 2003; Hardeland, 2005). Accordingly this study was essentially focused on discovering of the possible

\section{Dopamine}

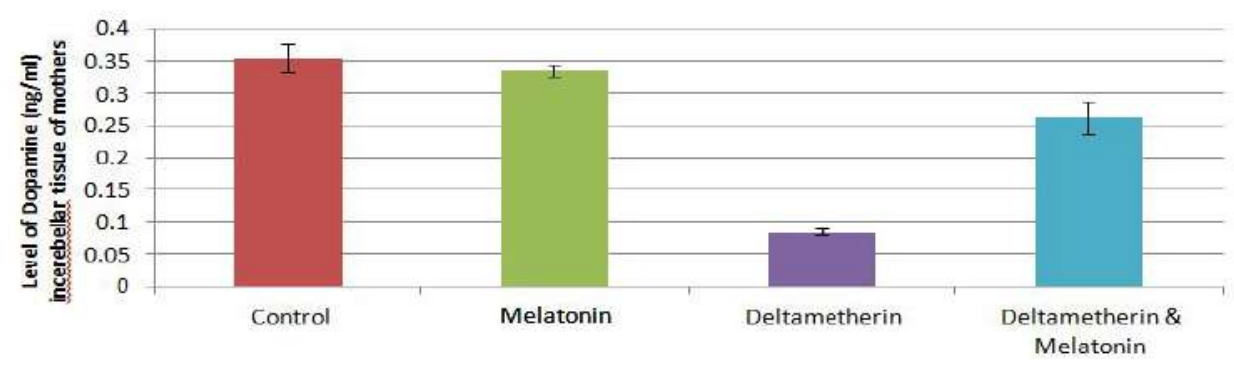

Figure 21: Illustrating the mean value of eclcicrral ebrrec dopamine among the different studied groups of mothers rats.

\section{Dopamine}

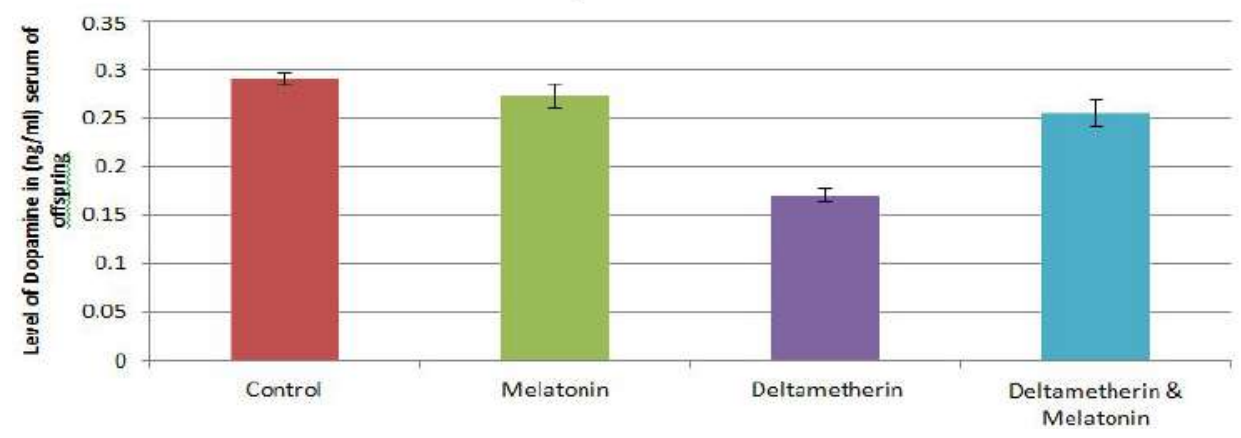

Figure 22: Illustrating the mean value of eclcicrral ebrrec dopamine among the different studied groups of 21 days old rats.

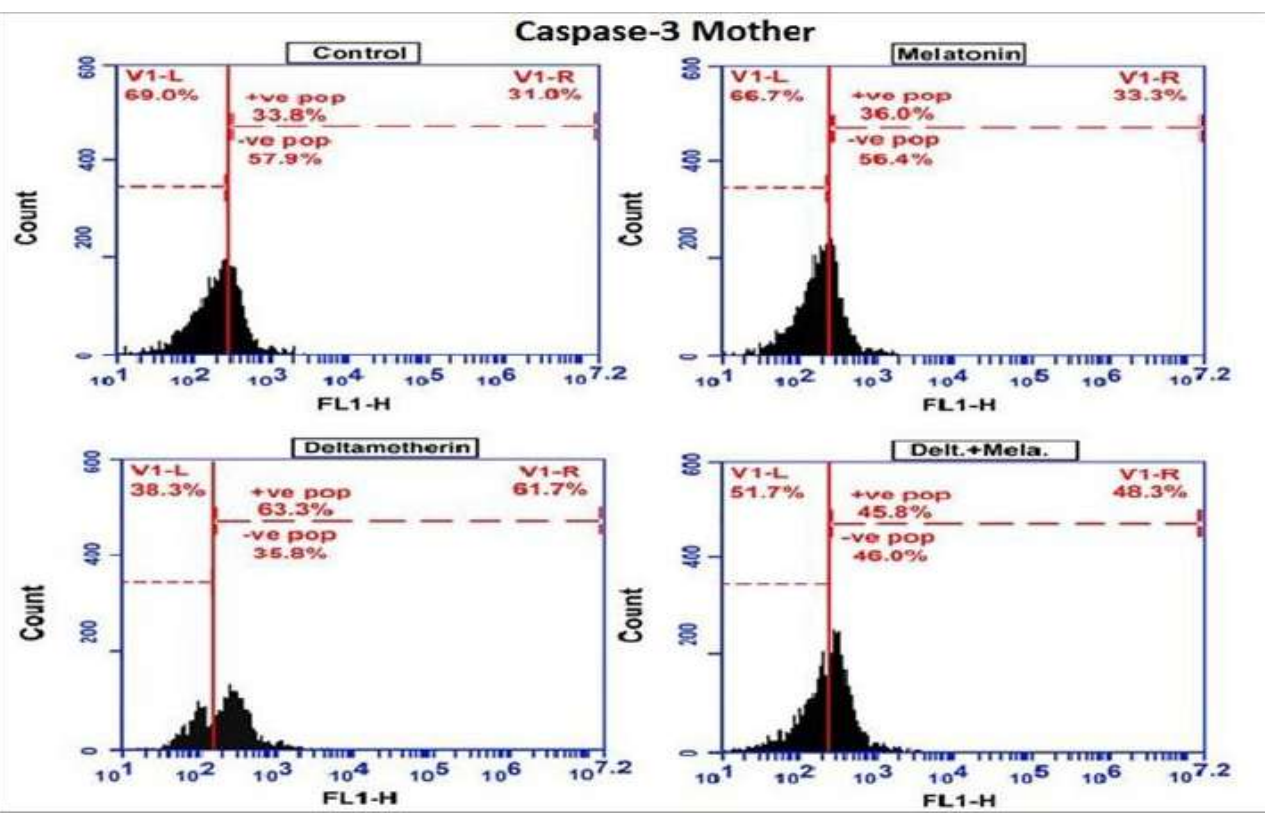

Figure 23: A flow cytometric chart illustrating the mean \% value of caspase-3 activity in the cerebellar tissue of mothers rats among different studied groups. 


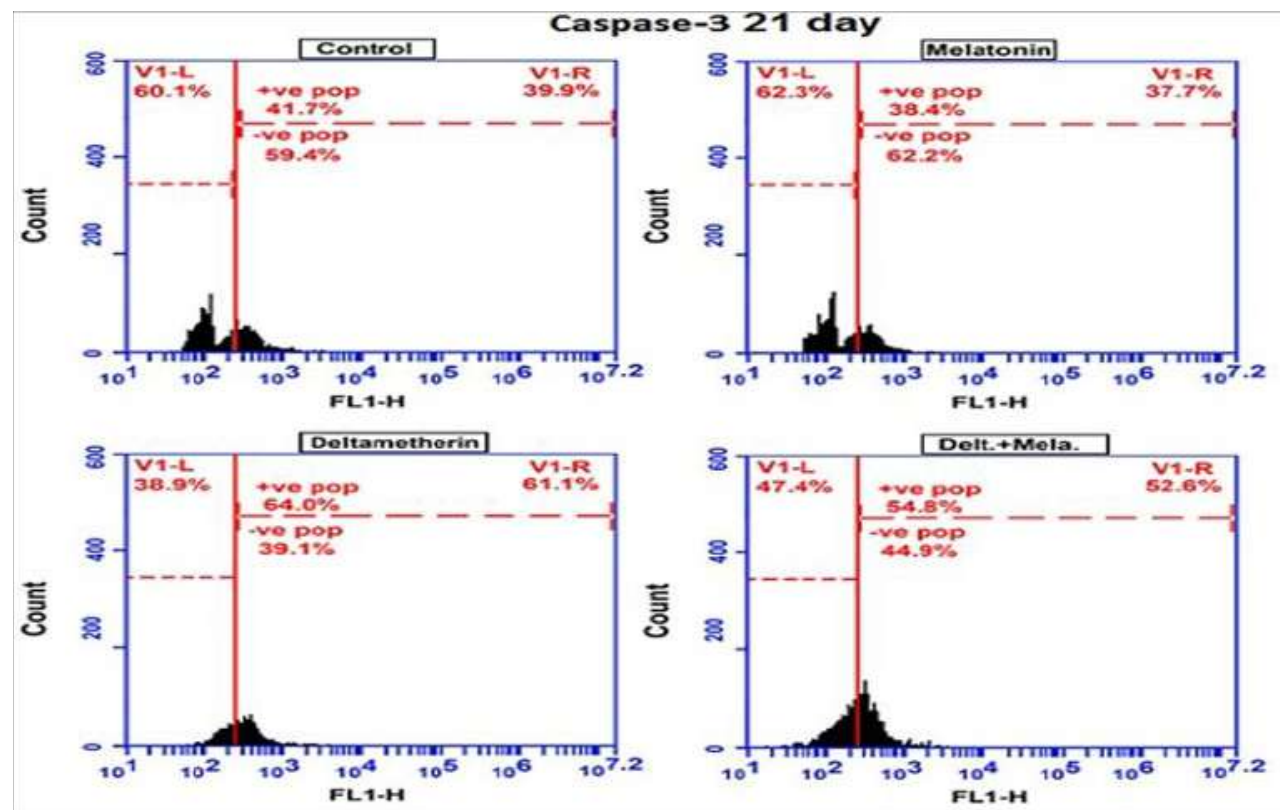

Figure 24: A flow cytometric chart illustrating the mean $\%$ value of caspase- 3 activity in the cerebellar tissue of 21 th days old rats among different studied groups.

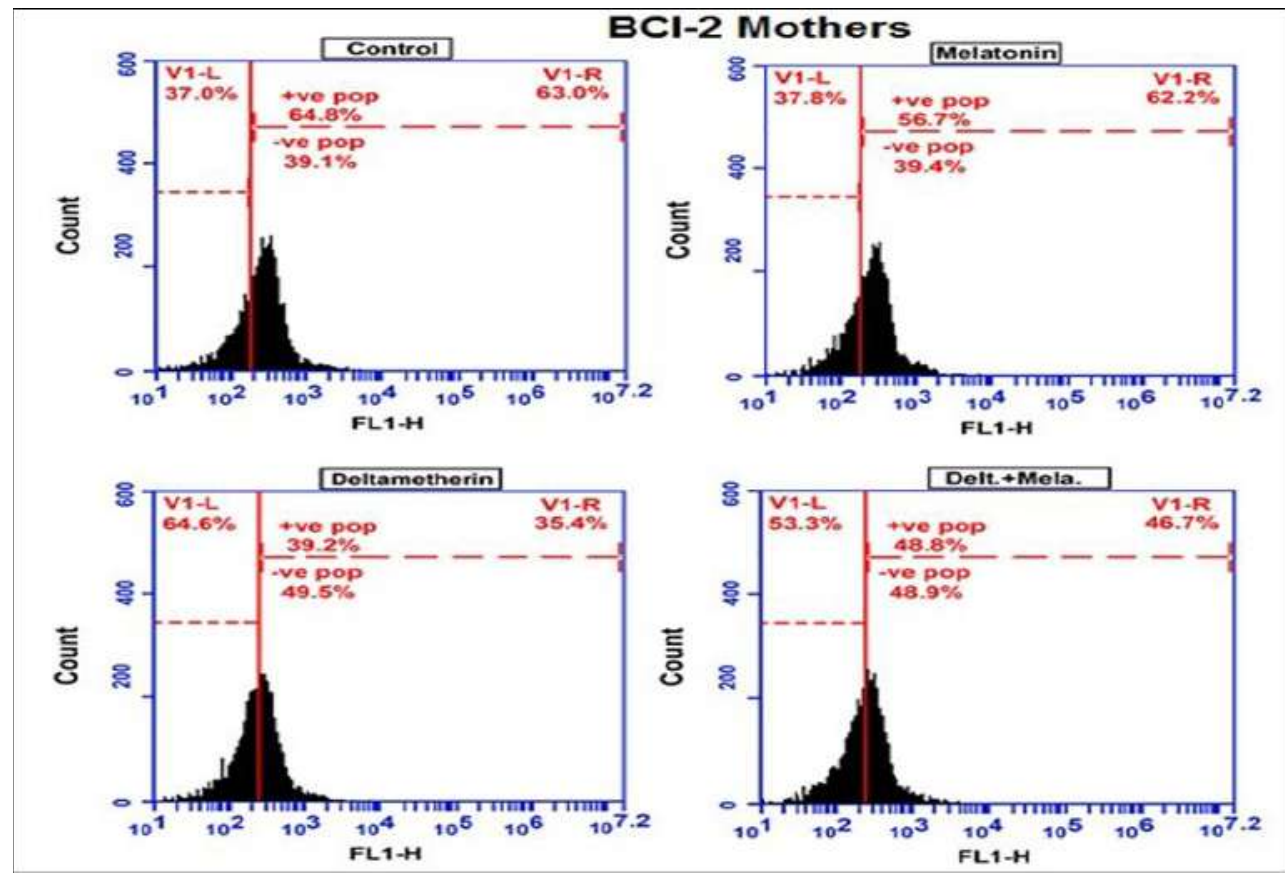

Figure 25: A flow cytometric chart illustrating the mean $\%$ value of $\mathrm{BCl}-2$ activity in the cerebellar tissue of mothers rats among different studied groups.

ameliorative role of melatonin against deltamethrin-induced cerebellar neurotoxicity in mother's rats and their offspring.

The result of the present work revealed that the mean body weights of deltamethrin-treated mother's rats and their offspring were significantly lower than those of control. The obtained results are in agreement with the previous researchers (Kalender et al., 2007; Uzunhisarcikli et al., 2007) who elucidated that consumption of pyrethroid compounds could inhibit the growth rate through their inhibitory effects on the appetite center leading to decrease in food consumption. Other study revealed that deltamethrin can lower the body weight via the mechanism involving disturbance in metabolic enzymes (Issam et al., 2012). In the current work, regularsupplementation of melatonin post deltamethrin treatment for mother's rats showed obvious recovery in their body weight. Wolden-Hanson (2000) declared that melatonin has a powerful role in maintaining the body weight through quick and easy assimilation of all the nutrients found in the blood stream and induction of daily physical activity.

In the present study, deltamethrin induced several histological alterations in the cerebellum of mother's rats and their offspring. These changes were represented by loss of Purkinje cells or their degeneration in addition to remarkable vacuolation and pyknosis as well as apoptosis among granular and molecular cells. These 

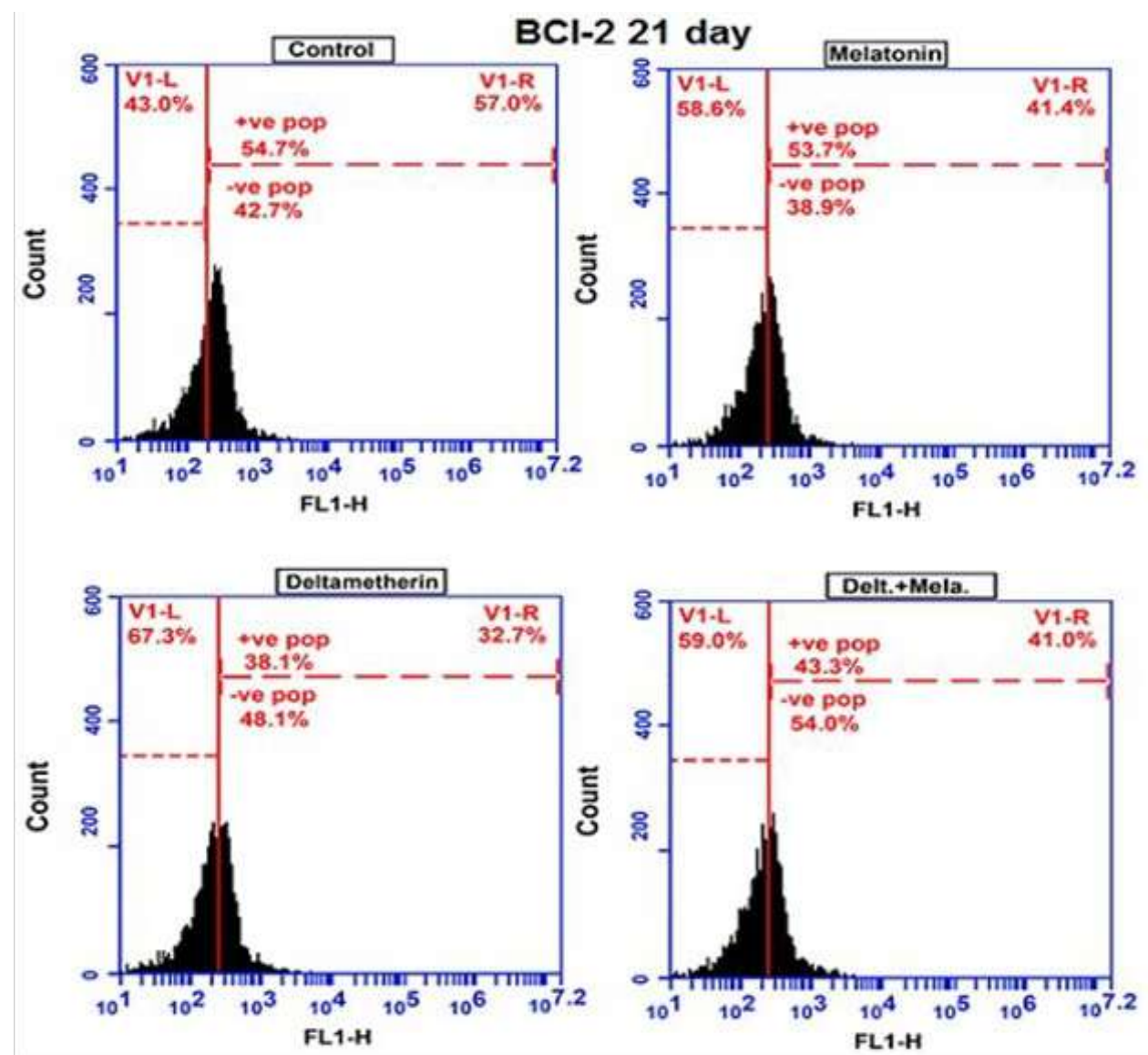

Figure 26: A flow cytometric chart illustrating the mean $\%$ value of $\mathrm{BCl}-2$ activity in the cerebellar tissue of 21 th days old rats among different studied groups.

findings go parallel with the study of Aiguo and Yugu (2000) and Ercüment et al. (2010) who found that deltamethrin can induce neuro-degenerative changes and apoptotic cell death in rat brain. Celik and Suzek, (2009) explained that histological alterations in the cerebellar cortex under the influence of deltamethrin was mainly attributed to its oxidative damage. They also added that pyrethroids could penetrate the cell membrane easily, generate various free radicals as superoxide radical, nitrogen species, nitricoxide and hydroxyl radical thus causing neurodegenerative effects. Moreover, Elhalwagy et al. (2008) explained that the released oxygen free radicals are implicated in destabilization and disintegration of cell membrane leading to cell death and apoptosis. The vacuolation appeared within the granular cell layers were described as spongiform changes (Husain, 2015). Other hypothesis considered this vacuolation as a type of cellular defense mechanism against neurotoxins within the cerebellar cortex (Eluwa et al., 2013). Yuan \&Yankner (2016) also, concluded that DM induced oxidative stress in cerebellum is also implicated in histopathological changes and are attributed to inflammation, necrosis, or accelerated apoptosis.

The immuno-histochemical results of the present work revealed a strong positive expression for GFAP and weak to moderate expression for synaptophysin (SYN) protein in the cerebellar cortex of deltamethrin-treated mother's rats and their offspring if compared with control.

GFAP is an intermediate filament protein of the mature astrocytes that forms a supportive network to neural cells in order to maintain their shape, motility, and function. Previous studies discussed that any neurotoxins can induce astrocyte proliferation and hypertrophy with increased production of GFAP resulting in severe astrogliosis (Eng et al., 2000; Onaolapo et al., 2017). Other studies reported that, astrocytes over- activation may lead to over-production of nitro oxide (NO) that causes excess GFAP expression (Saad El-Dien et al., 2010; Hashem et al., 2012).

Synaptophysin (SYN) is an integral membrane protein of synaptic vesicles that maintains synaptic transmission and playing an important regulatory role in synaptogenesis (Webster et al., 2001). SYN is mainly localized at the synapses of the axons of granular cells and dendrites of Purkinje cells in the cerebellar cortex (Leclerc et al., 1989). Strong or moderate SYN immune-reactivity is usually associated with regular neurotransmission of nerve impulses (King \& Arendash, 2002). On the other hand, weak SYN reactivity indicates abnormal axon transport and impaired synaptic function resulting in cognitive deficits (Ferrer et al., 2000). In the current work, the decreased expression of SYN could be due to a possible inhibition of SYN protein biosynthesis through DNA fragmentation induced by deltamethrin metabolites.

Melatonin is one of the strongest antioxidants hormones whereas, it is considered as free radical scavenger leading to attenuation of oxidative stress. Thus, it has a strong chemoprotective, immunostimluatory effect to neurons (Winiarska et al., 2006; Motawi et al., 2017). In the present study, examination of stained cerebellar sections of deltamethrin rats that simultaneously 
supplemented with melatonin displayed apparently reversed most of the immunohistochemical and histopathological alterations induced by deltamethrin.

Generally most organisms widely use antioxidants like GSH, SOD, catalase and other antioxidants to protect themselves against liberated free radicals (Andersen 2004, Augustyniak and Skrzydlewska 2004).

Exposure of pregnant mother's rats to deltamethrin in this study led to increased level of serum MDA and, a significant decrease in antioxidant enzymes (GSH, catalase and SOD). These results go parallel with the finding of other studies (Somia et al., 2010; Oliveira et al., 2018). Their study confirmed that deltamethrin can decrease the antioxidant status (GSH, catalase, SOD) in many body organs especially lungs, liver, kidneys and cerebellum which correlated with histopathological changes induced by deltamethrin in these organs. Eradal et al. (2002) explained that organophosphorous compounds and pyrethroids can induce oxidative stress via over-production of reactive oxygen species (ROS) that interact with the vital cellular macromolecules like DNA, protein and lipid causing changes in the cell structure and function. Other study revealed that exposure to the pyrethroids cause liberation of excess free radicals that accumulate in the cell resulting in changes in antioxidant defense mechanisms; including detoxification or induction of peroxidation and subsequently interaction between the ROS and cell membranes (Abdel Daim et al., 2015). The reduction in serum GSH on exposure to deltamethrin was mainly attributed to the ligation of GSH with liberated free radicals or to an increased breakdown of GSH (Rouabhi et al., 2015; Henine et al., 2016). Yuan et al. (2016) added that, the reduction in the level of GSH is accompanied with increased rate of cytotoxicity whereas, GSH plays an important role in the detoxification induced by any extrinsic or intrinsic factors. Gadoth et al. (2011) explained that the metabolism of the pyrethroids can liberate ROS, which in turn could lead to an increased lipid peroxidation MDA and a consequence of the depletion of GSH.

Post-treatment of melatonin with deltamethrin in this work caused a significant decrease in serum MDA level and a significant increase in GSH, catalase and SOD levels. These results were in accordance with the findings of Sun et al. (2008) who revealed that melatonin has an ameliorative effect on deltamethrin-induced oxidative damage in brain. Also, it has been documented that exogenous melatonin increases the activities of GSH, CAT and SOD in cerebellum (Romero et al., 1999; Tan et al., 2000). Moreover, melatonin is a powerful antioxidant hormone whereas; it activates the enzymes responsible for cellular defense systems (Eşrefoğlu et al., 2011). Since it can readily cross the $\mathrm{BBB}$ and enter the neurons when administered exogenously. Melatonin has a high ability to detoxify ROS and inhibits the oxidative stress directly through its ability to attack free radicals (Wakatsuki \& Okatani, 2000), and indirectly by stimulation the production of antioxidants (Manfredi \& Beal, 2000). In addition, the phenol group of melatonin can detoxify lipid radicals.

In the current work a remarkable decrease in the levels of serum glutamate and serotonin was noticed among the deltamethrin treated mothers and their offspring in comparing with control.
Serotonin or 5-hydroxytryptamine $(5-\mathrm{HT})$ is an essential monoamine neurotransmitter that plays a crucial role in regulation of several behavioral and physiological functions like mood, sleep, body temperature, appetite, aggression, and sexual behavior (Young, 2007). In cerebellum, serotonin plays a role in regulation of neuronal activity, synaptic transmission and cerebellar development. In the current study, the decreased level of serum serotonin under the influence of deltamethrin may be due to the potential role of deltamethrin to stimulate calcium influx in cerebellar neurons through prolonged open calcium channels (Cao et al., 2011). Moreover, the reduced level of serotonin may be implicated in loss of appetite (Young, 2007) for deltamethrin treated- mother's rats and their offspring leading to their weight loss which in accordance with the obtained result.

Glutamate is the anion form of glutamic acid. It plays a major role in neuro- transmission of signals in some area of brain, especially in the Purkinje and granular cells of cerebellum (Meldrum, 2000). Also, glutamate plays critical role in the regulation of synaptogenesis during early brain development (Okubo et al., 2010). The remarkable reductions in glutamate level under the influence of deltamethrin in this study may be attributed to loss of Purkinje cells under the influence of oxidative stress induced by deltamethrin (Kyriakopoulos et al., 2008; Maloku et al., 2010). McKimm et al. (2014) confirmed that developmental loss of cerebellar Purkinje cells leads to reductions in glutamate release in cerebellar efferent pathways that subsequently influence dopamine release.

Dopamine is released by some nerve terminals and functions as a neurotransmitter among nerve cells of the brain. Dopamine deficiency leads to Parkinson's disease and schizophrenia (Berridge et al., 2009). In the current work a highly significant decrease in the level of cerebellar tissue dopamine was recorded among deltamethrin-treated mother's rats and their offspring if compared with control. Similar finding was recorded by Kirby et al. (1999) who explained that deltamethrin and other pyrethroid are potent neurotoxins for dopaminergic nerve terminals through their exerting augmentation release of dopamine and glutamate from nerve terminals into the blood. In addition, prolonged exposure to deltamethrin can decrease dopamine uptake by the nerve cells, which may be attributed to induction of apoptosis. In contrast to our results, it has been found that exposure of mice to deltamethrin resulted in an elevation in dopamine uptake which possibly indicative of an up-regulation of dopamine transmission (Karen et al., 2001). Such conflict of results may be attributed to the variation in exposed dose of deltamethrin or to the condition of experiment.

Altered expression of caspases, P53, Bax, and Bcl-2 play a crucial role in induction of apoptosis. Bcl-2 is an anti-apoptotic protein while caspase- 3 is a strong apoptotic enzyme (Cory \& Adams, 2002; Wu et al., 2003; Hossain \& Richardson, 2011). The sequential activation of Caspases plays an important role in progress of apoptosis (Kumar et al. 2015; Jevtić et al. 2016). The obtained results confirmed that treatment of mothers rats with deltamethrin induced high levels Caspase- 3 and significant decrease in Bcl-2 followed by apoptosis. This is confirmed by histopathological changes in the cells of cerebellar cortex. Such apoptosis was reduced with supplementation of melatonin. The 
obtained results are in line with the finding of Kassab (2018). Yuan \&Yankner (2016) reported that oxidative stress induced by deltamethrin is implicated in acceleration of neuronal cell apoptosis. Also, recent studies declared that, melatonin has powerful anti-apoptotic effects through its free radical scavenger activity (Chang et al., 2018).

\section{CONCLUSION}

Based on our results, exposure to deltamethrin during gestation and weaning period leads to various deleterious alterations in histological, immunohistochemical and biochemical aspects of cerebellum for mothers and their offspring. Melatonin is a powerful antioxidant hormone that successfully ameliorated the cerebellar disorders induced by deltamethrin. Accordingly, it is recommended that the Ministry of Agriculture and Ministry of Health should be cooperated with each other to introduce the safety tools for peoples dealing with insecticides especially deltamethrin to protect them against their toxicity.

\section{REFERENCES}

1. Ascherio, A., Chen, H., Weisskopf, M. G., O’Reilly, E., McCullough, M. L., et al. (2006). Pesticide exposure and risk for Parkinson's disease. Ann. Neurol., 60: 197-203.

2. Baldi, I., Cantagrel, A., Lebailly, P., Tison, F., Dubroca, B., et al. (2003). Association between Parkinson's disease and exposure to pesticides in southwestern France. Neuroepidemiology., 22: 305-310.

3. Varol, S., Özdemir, H. H., Çevik, M. U., Altun, Y., Ibiloglu, I., et al., (2016). Protective effects of lglutamine against toxicity of deltamethrin in the cerebral tissue. Neuropsychiatr. Dis. Treat., 12: 1005-1011.

4. Soderlund, D. M., Smith, T. J., Lee, S. H., (2000). Differential sensitivity of sodium channel isoforms and sequence variants to pyrethroid insecticides. Neurotoxicol., 21:127-137.

5. Tu, H.T., Silvestre, F., Bernard, A., Douny, C., Phuong, N. T., et al., (2007). Oxidative stress response of black tiger shrimp (Penaeusmonodon) to enrofloxacin and to culture system. Aquaculture., 285: 244-224.

6. Gündüz, E., Ülger, B.V., 'Ibiloglu, I., Ekinci, A., Dursun, R., et al. (2015). Glutamine provides effective protection against deltamethrin- induced acute hepatotoxicity in rats but not against nephrotoxicity. Med. Sci. Monit., 21: 1107-1114.

7. Oda, S.S., El-Maddawy, Z., (2012). Protective effect of vitamin $\mathrm{E}$ and selenium combination on deltamethrininduced reproductive toxicity in male rats. Exp. Toxicol. Pathol., 64: 813-819.

8. Gasmi, S., Rouabhi, R., Kebieche, M., (2016). Deltamethrin induced neurodegeneration and behavioral effect by dysfunction cytosolic antioxidant system in rats brain. Alger. J. Nat. Sci., 1: 14-22.

9. Khalatbary, A. R., Mohammadnegad, B., Ghaffari, E., Rafiei, A., (2015). Oleuropein Attenuates Deltamethrininduced Apoptosis in Rat Cerebellar Purkinje Neurons. Res. Mol. Med., 3: 1-7.
10. Kumar, A., Sasmal, D., Sharma, N., (2018). Mechanism of deltamethrin induced thymic and splenic toxicity inmice and its protection by piperine and curcumin: In vivo study. Drug. Chem. Toxicol. 41: 33-41.

11. Joya, J., Sangha, G. K., (2016). Development and behavioural toxicity of deltamethrin on Rattus norvegicus following gestational exposure. J. Appl. \& Nat. Sci., 8: 40-45.

12. Patro, N., Patro, I. K., (2005). Effects of deltamethrin on granule cell migration during postnatal development of rat cerebellum. Indian. J. Exp. Biol., 43: 158-162.

13. Latuszyñska, J., Luty, S., Raszewski, G., Tokarska-Rodak, M., Przebirowska, D., et al., (2001). Neurotoxic effect of dermally-applied chlorpyrifos and cypermethrin in Wistar rats. Ann. Agric. Environ. Med., 8: 163-170.

14. Abdel-Rahman, A., Dechkovskaia, A. M., Goldstein, L. B., Bullman, S. H., Khan, W., El-Masry, E. M., Abou- Donia, M. B., (2004). Neurological deficits induced by malathion, DEET, and permethrin, alone or in combination in adult rats. J. Toxicol. Environ. Health., 67: 331-56.

15. Narahashi, T., (2000). Neuroreceptors and ion channels as the basis for drug action: past, present, and future. $J$. Pharmacol. Exp. Ther., 294: 1-26.

16. Soderlund, D. M., Clark, J. M., Sheets, L. P., Mullin, L. S., Piccirillo, V. J., et al., (2002). Mechanisms of pyrethroid neurotoxicity: implications for cumulative risk assessment. Toxicology., 171: 3-59.

17. Gasmi, S., Rouabhi, R., Kebieche, M., (2016). Deltamethrin induced neurodegeneration and behavioral effect by dysfunction cytosolic antioxidant system in rats brain. Alger. J. Nat. Sci., 1: 14-22.

18. Takasaki, I., Oose, K., Otaki, Y., Ihara, D., Fukuchi, M., et al. (2013). Type II pyrethroid deltamethrin produces antidepressant- like effects in mice. Behav. Brain. Res., 257: 182-188.

19. Pang, S. F, Allen, A. E., (1986). Extra-pineal melatonin in the retina: Its regulation and physiological function. Pineal. Res. Rev., 4:55.

20. Acuña-Castroviejo, D., Escames, G., Venegas, C., DíazCasado, M. E., Lima-Cabello, E., et al. (2014). Extrapineal melatonin: sources, regulation, and potential functions. Cell. Mol. Life. Sci., 71: 2997-3025.

21. Tahan, V., Atug, O., Akin, H., (2009). Melatonin ameliorates methionine choline deficient diet induced nonalcoholic steatohepatitis in rats. J. Pineal. Res., 46: 401-407.

22. Chawla, S. L., Rao, M. V., (2012). Protective effect of melatonin against fluoride- induced oxidative stress in the mouse ovary. Res. Rep. Fluoride., 45: 125-132.

23. Dubocovich, M. L., (1983). Melatonin is a potent modulator of dopamine release in the retina. Nature., 306:782.

24. Wiechmann, A. F., (1986). Melatonin: Parallels in pineal gland and retina. Exp. Eye. Res., 42: 507.

25. Suzen, S., (2006). Recent developments of melatonin related antioxidant compounds. Comb. Chem., 9: 409-419. 
26. Uyanikgil, Y., Baka, M., Ateş, U., Turgut, M., Yavaşoğlu, A., et al. (2007). Neuroprotective effects of melatonin upon the offspring cerebellar cortex in the rat model of BCNUinduced cortical dysplasia. Brain. Res., 1160: 134-144.

27. Cardinali, D. P., Furio, A. M., Reyes, M. P., (2005). Clinical perspectives for the use of melatonin as a chronobiotic and cytoprotective agent. Ann. NY. Acad. Sci., 1057:327-336.

28. Kabadi, S. V., Maher, T. J., (2010). Post-treatment with uridine and melatonin following traumatic brain injury reduces edema in various brain regions in rats. Ann. N. Y. Acad. Sci., 1199: 105-113.

29. Fernández, A., Ordóñez, R., Reiter, R. J., González-Gallego, J., and Mauriz, J. L., (2015). Melatonin and endoplasmic reticulum stress: relation to autophagy and apoptosis. $J$. Pineal. Res., 59: 292-307.

30. Dong, Y., Fan, C., Hu, W., Jiang, S., Ma, Z., et al. (2016). Melatonin attenuated early brain injury induced by subarachnoid hemorrhage via regulating NLRP3 inflammasome and apoptosis signaling. J. Pineal. Res., 60: 253-262.

31. Reiter, R. J., Tan, D. X., Leon, J., Kilic, U., Kilic, E., (2005). When melatonin gets on your nerves: its beneficial actions in experimental models of stroke. Exp. Biol. Med., 230: 104-107.

32. Crespi, F., Ratti, E., Trist, D. G., (1994). Melatonin, a hormone monitorable in vivo by voltammetry? Analyst., 119: 2193- 2197.

33. Hala, A., Nouf, M. I., Faddah, L. M., (2009). Ameliorating effect of idebenone and/ or melatonin against oxidative stress and energy depletion in brain of hypoxic rats. J. Res. Med. Medic. Sci., 4: 263- 277.

34. Aiguo, W., Yugu, L., (2000). Apoptotic cell death in rat brain following deltamethrin treatment. Neuroscience. Letters., 279: 85-88.

35. Sheets, L. P., Doherty, J. D., Law, M. W., Reiter, L. W., Crofton, K. M., (1994). Age-dependent differences in the susceptibility of rats to deltamethrin. Toxicol. Appl. Pharmacol., 12: 186-190.

36. Bancroft, J. D., Gamble, M., (2008). Theory and practice of histological techniques. Elsevier Health Sciences.

37. Koroliuk, M. A., Ivanova, L. I., Maiorova, G. I., (1988). A method of determining catalase activity. Laboratornoe. Delo., 1: 16-19.

38. Ellman, G. L., (1959). Tissue sulphydryl groups. Arch. Biochem. Biophys., 82: 70-77.

39. Placer Z. A., Cushman, L. L., Johnson, B. C., (1966). Estimation of product of lipid peroxidation (malonyl dialdehyde) in biochemical systems. Anal. Biochem., 16: 359-364.

40. Newell, J. O., Cessna, M. H., Greenwood, J., Hartung, L., Bahler, D. W., (2003). Importance of CD117 in the evaluation of acute leukemias by flow cytometry. Cytometry., 52: 40-43.

41. Kim, K. B., Anand, S. S., Kim, H. J., (2008). Toxicokinetics and tissue distribution of deltamethrin in adult SpragueDawley rats. Toxicol. Sci., 101: 197-205.

42. Patro, N., Mishra, S. K., Chattopadhyay, M., Patro, K., (1997).Neurotoxicological effects of deltamethrin on the postnatal development of cerebellum of rat. J. Biosci., 22: 117-130.

43. Wang, L. M., Suthana, N.A., Claudhurg, D., (2005). Melatonin inhibits hippocampal long- term potentation. Eur. J. Neuroscience., 22: 2231-2237.

44. Hataya, Y., Akamizu, T., Takaya, K., Kanamoto, N., Ariyasu, H., et al. (2001). A low dose of ghrelin stimulates growth hormone $(\mathrm{GH})$ release synergistically with GH-releasing hormone in humans. J. Clin. Endocr. Metab., 86: 4552-4555.

45. Tan DX, Manchester LC, Hardeland R, Lopez-Burillo S, Mayo JC, et al., (2003). Melatonin: a hormone, a tissue factor, an autocoid, a paracoid, and an antioxidant vitamin. J. Pineal. Res., 34:75-78.

46. Hardeland, R., (2005). Antioxidative protection by melatonin: multiplicitymof mechanisms from radical detoxification to radical avoidance. Endocrine., 27: 119-130.

47. Kalender, S., Kalender, Y., Durak, D., (2007). Methyl parathion induced nephrotoxicity in male rats and protective role of vitamins C and E. Pestic. Biochem. Physiol., 88: 213-218.

48. Uzunhisarcikli, M., Kalender, Y., Dirican, K., (2007). Acute, subacute and subchronic administration of methyl parathioninduced testicular damage in male rats and protective role of vitamins C and E. Pestic. Biochem. Phys., 87: 115-122.

49. Issam, C., Intissar, G., Fatma, B., Yahia, H. M, Samir, H., et al. (2012). Oxidative stress, biochemical and histopathological alterations in the liver and kidney of female rats exposed to low doses of deltamethrin (DM): a molecular assessment. Biomed. Environ. Sci., 25: 672-683.

50. Ercüment, A., Saltuk, B., Orhan, E., (2010). Acute and long-term genotoxicity of deltamethrin to insulin-like growth factors and growth hormone in rainbow trout. Comp. Biochem. Physiol. C. Toxicol. Pharmacol., 152: 451-455.

51. Celik, I., Suzek, H. (2009). Effects of subacute exposure of dichlorovos at sublethal dosages on erythrocyte and tissue antioxidant defense systems and lipid peroxidation in rats. Ecotoxicol. Environ. Saf., 72: 905-908.

52. Elhalwagy, M. E. A., Darwish, E. M., Zaher, N. S., (2008). Prophylactic effects of green tea polyphenols against liver and kidney induced by feitrothion insecticide. Pest. Biochem. Physiol., 91: 81-89.

53. Eluwa, M. A., Inyangmme, II, Akpantah, A. O., Ekanem, T. B., Ekong, M. B., et al., (2013). A comparative study of the effect of diet and soda carbonated drinks on the histology of the cerebellum of adult female albino wistar rats. Afr. Health. Sci., 13: 541-545.

54. Yuan, J., Yankner, A., (2016). Apoptosis in the nervous system. Nature. 407: 802-809.

55. Eng, L., Ghirnikar, R., Lee, Y., (2000). Glial fibrillary acidic 
protein: GFAP-thirty-one years (1969-2000). Neurochem. Res., 25:1439-1451.

56. Onaolapo, A. Y., Onaolapo, O. J., Nwoha, P. U., (2017). Methyl aspartylphenylalanine, the pons and cerebellum in mice: An evaluation of motor, morphological, biochemical, immunohistochemical and apoptotic effects. J. Chem. Neuroanat., 86:67-77.

57. Saad El-Dien, H. M., El Gamal, D. A., Heba, A., Mubarak, H. A., Samira, M., Saleh, S. M., (2010) Effect of Fluoride on Rat Cerebellar Cortex: Light and Electron Microscopic Studies. Egypt. J. Histol., 33: 245-256.

58. Hashem, H. E., Safwat, M. D., Algaidi, S. (2012). The effect of monosodium glutamate on the cerebellar cortex of male albino rats and the protective role of vitamin $\mathrm{C}$ (histological and immunohistochemical study). J. Mol. Hist., 43:179-186.

59. Webster, M. J., Shannon, W, C., Herman, M. M., Hyde, T. M., Kleinman, J. E., (2001). Synaptophysin and GAP-43 mRNA levels in the hippocampus of subjects with schizophrenia. Schizophr. Res., 49: 89-98.

60. Leclerc, N., Beesley, P. W., Brown, I., Colonnier, M., Gurd, J. W., et al. (1989). Synaptophysin expression during synaptogenesis in the rat cerebellar cortex. J. Comp. Neurol., 280: 197-212.

61.King, D. L., Arendash, G. W., (2002). Synaptophysin immunoreactivity in $\mathrm{Tg} 2576$ transgenic mice during aging, correlations with cognitive impairment. Brain. Res., 926: 58-68.

62. Ferrer, I., Puig, B., Blanco, R., Marti, E., (2000). Prion protein deposition and abnormal synaptic protein expression in the cerebellum in Creutzfeldt-Jakob disease. Neuroscience., 97: 715-726.

63. Winiarska, K., Fraczyk, T., Malinska, D., Drozak, J., Bryla, J., (2006). Melatonin attenuates diabetes- induced oxidative stress in rabbits. J. Pineal. Res., 40: 168-176.

64. Motawi., T. K., Ahmed, S. A., Ahamed, M., El- Maraghy, S. A., Aziz, W., (2017). Melatonin and/or rowatinex attenuate streptozotocin-induced diabetic renal injury in rats. $J$. Biomed. Res., 0(0): 1-9.

65. Andersen, J. K. (2004). Oxidative stress in neurodegeneration: cause or consequence? Nat. Med., 10: 18-25.

66. Augustyniak, A., Skrzydlewska., (2004). Antioxidative abilities during aging. Postepy Hig Med Dosw., 58: 194-201.

67. Somia, I., Hamady, A., Nabila, S., (2010). Effect of anthum Graveoles L. extract on biochemical and histopathological alteration of deltamethrin in rats. J. Bioanal. Biomed., 2: 8-12.

68. Oliveira, J. M., Losano, N. F., Condessa, S. S., de Freitas, R. M. P., Cardoso, S. A., et al., (2018): Exposure to deltamethrin induces oxidative stress and decreases of energy reserve in tissues of the Neotropical fruit-eating bat Artibeus lituratus. Ecotoxicol. Environ. Saf., 148:684-692.

69. Eradal, K., Fatih, G., Mehmet, A., (2002). Protective role of melatonin and a combination of vitamin $\mathrm{C}$ and vitamin $\mathrm{E}$ on lung toxicity induced by chlorpyrifos- ethyl in rats. Exp. Toxic. Pathol., 54: 97-108.

70. AbdelDaim, M., Abdelkhalek, M., Hassan, M., (2015). Antagonistic activity of dietary allicin against deltamethrin-induced oxidative damage in freshwater Nile tilapia; Oreochromis niloticus. Ecotoxicol. Environ. Saf., 111: 146 -152.

71. Henine, S., Rouabhi, R., Gasmi, S., Amrouche, A., Abide, A., et al. (2016). Oxidative stress status, caspase-3, stromal enzymes and mitochondrial respiration and swelling of Paramecium caudatum in responding to the toxicity of Fe3O4 nanoparticles. Environ. Health. Sci., 8: 161.

72. Gadoth, N., Gobel, H., (2011). Oxidative Stress and Free Radical Damage in Neurology. Springer Science., 514: 91.

73. Romero, M. P., Osuna, C., Garcia-Perganeda, A., (1999). The pineal secretory product melatonin reduces hydrogen peroxideinduced DNA damage in U-937 cells. J. Pineal. Res., 26:227-235.

74. Eşrefoğlu, M., Gul, M., Ateş, B., Erdoğan, A., (2011). The effects of caffeic acid phenethyl ester and melatonin on agerelated vascular remodeling and cardiac damage. Fundam. Clin. Pharmacol., 25: 580-590.

75. Wakatsuki, A., Okatani, Y., (2000). Melatonin protects against the free radical-induced impairment of nitric oxide production in the human umbilical artery. J. Pineal. Res., 28: 172-178.

76. Manfredi, G., Beal, M. F., (2000). The role of mitochondria in the pathogenesis of neurodegenerative diseases. Brain. Pathol., 10: 462-472.

77. Young, S. N., (2007). How to increase serotonin in the human brain without drugs. J. Psychiatry. Neurosci., 32: 394-399.

78. Cao, Z., Shafer, T. J., Murray, T. F., (2011). Mechanisms of pyrethroid insecticide-induced stimulation of calcium influx in neocortical neurons. J. Pharmacol. Exp. Ther., 336:197-205.

79. Meldrum, B. S., (2000). Glutamate as a neurotransmitter in the brain: review of physiology and pathology. J. Nutri., 130: 1007-1015.

80. Okubo, Y., Sekiya, H., Namiki, S., Sakamoto, H., Iinuma, S., et al., (2010). Imaging extrasynaptic glutamate dynamics in the brain. Proc. Natl. Acad. Sci. USA., 107: 6526-6531.

81. Kyriakopoulos, M., Vyas, N. S., Barker, G. J., Chitnis, X. A., Frangou, S. (2008). A diffusion tensor imaging study of white matter in early onset schizophrenia. Biol. Psychiatry., 63:519-523.

82. Maloku, E., Covelo, I. R., Hanbauer, I., Guidotti, A., Kadriu, B., et al. (2010). Lower number of cerebellar Purkinje neurons in psychosis is associated with reduced reelin expression. Proc. Natl. Acad. Sci., 107:4407-4411.

83. McKimm, E. J., Beau, C., Dan, G., Lorraine, M., Guy M. (2014). Glutamate dysfunction associated with 
developmental cerebellar damage: Relevance to autism spectrum disorders. Cerebellum., 13: 346-353.

84. Berridge, K. C., Robinson, T. E., Aldridge, J. W., (2009). Dissecting components of reward: 'liking', 'wanting', and learning.Curr. Opin. Pharmacol., 9: 65-73.

85. Kirby, M. L., Castagnoli, K., Bloomquist, J. R., (1999). In Vivo Effects of Deltamethrin on Dopamine Neurochemistry and the Role of Augmented Neurotransmitter Release. Pest. Biochem. Physiol., 65: 160-168.

86. Karen, D. J., Li, W., Harp, P. R., Gillette, J. S., Bloomquist, J. R., (2001). Striatal dopaminergic pathways as a target for the insecticides permethrin and chlorpyrifos. Neurotoxicology., 22:811-817.

87. Cory, S., Adams, J. M., (2002). The Bcl-2 family: regulators of the cellular life-or-death switch. Nat. Rev. Cancer., 2: 647-656.

88. Wu, A., Li, L., Liu, Y., (2003). Deltamethrin induces apoptotic cell death in cultured cerebral cortical neurons. Toxicol. Appl. Pharmacol., 187: 50-57.

89. Hossain, M. M., Richardson. J. R., (2011). Mechanism of pyrethroid pesticide-induced apoptosis: role of calpain and the ER stress pathway. Toxicol. Sci., 122: 512-525.

90. Kumar, A., Sasmal, D., Sharma, N. (2015). An insight into deltamethrin induced apoptotic calcium, p53 and oxidative stress signalling pathways. Toxicol. Environ. Health. Sci., 7:25.

91. Jevtić, G., Nikolić, T., Mirčić, A., Stojković, T., Velimirović, M., et al. (2016). Mitochondrial impairment, apoptosis and autophagy in a rat brain as immediate and long-term effects of perinatal phencyclidine treatment influence of restraint stress. Prog. Neuropsychopharmacol. Biol. Psychiatry., 3:87-96.

92. Kassab, A. A., (2018). Wheat germ oil attenuates deltamethrin-induced injury in rat cerebellar cortex: Histological and immunohistochemical study. EJH., 41: 182-191.

93. Chang, C., Huang, T., Chen, H., Huang, T., Lin, L., et al. (2018). Protective Effect of Melatonin against Oxidative Stress-Induced Apoptosis and Enhanced Autophagy in Human Retinal Pigment Epithelium Cells. Oxid. Med. Cell. Longev., 1:1-12.

94. Cao, Z., Shafer, T. J., Murray, T. F., (2011). Mechanisms of pyrethroid insecticide-induced stimulation of calcium influx in neocortical neurons. J. Pharmacol. Exp. Ther., 336:197-205.

95. Chang, C., Huang, T., Chen, H., Huang, T., Lin, L., et al. (2018). Protective Effect of Melatonin against Oxidative Stress-Induced Apoptosis and Enhanced Autophagy in Human Retinal Pigment Epithelium Cells. Oxid. Med. Cell. Longev., 1:1-12.

96. Husain, S. M. D., (2015). Neurohistological effects of lead on pons of adult albimo rat. GJRA., 4; 452-453.

97. Tan, D. X., Manchester, L. C., Reiter, R. J., (2000). Melatonin directly scavenges hydrogen peroxide: a potentially new metabolic pathway of melatonin biotransformation. Free. Radic. Biol. Med., 29:1177-1185.

98. Hanson, W. T., Mitton, D. R., McCants, R. L., (2000). Endocrinology., 141: 487-497. 